\title{
Nuclear Receptor Nr4a1 Regulates Striatal Striosome Development and Dopamine $\mathrm{D}_{1}$ Receptor Signaling
}

\author{
Maria-Daniela Cirnaru, ${ }^{1 "}$ CChiara Melis, ${ }^{1 "}$ Tomas Fanutza, ${ }^{1}$ Swati Naphade, ${ }^{2}$ Kizito-Tshitoko Tshilenge, ${ }^{2}$ \\ Brian S. Muntean, ${ }^{3}$ - Kirill A. Martemyanov, ${ }^{3}$ Joshua L. Plotkin, ${ }^{4}$ Lisa M. Ellerby, ${ }^{2}$ and Michelle E. \\ Ehrlich ${ }^{1}$
}

\author{
https://doi.org/10.1523/ENEURO.0305-19.2019
}

${ }^{1}$ Department of Neurology, Icahn School of Medicine at Mount Sinai, New York, New York 10029, ${ }^{2}$ The Buck Institute for Research on Aging, Novato, California 94945, ${ }^{3}$ Department of Neuroscience, The Scripps Research Institute, Jupiter, Florida 33458, and ${ }^{4}$ Department of Neurobiology and Behavior, Stony Brook University, Stony Brook, New York 11794

\begin{abstract}
The GABAergic medium-size spiny neuron (MSN), the striatal output neuron, may be classified into striosome, also known as patch, and matrix, based on neurochemical differences between the two compartments. At this time, little is known regarding the regulation of the development of the two compartments. Nr4a1, primarily described as a nuclear receptor/immediate early gene involved in the homeostasis of the dopaminergic system, is a striosomal marker. Using Nr4a1-overexpressing and Nr4a1-null mice, we sought to determine whether Nr4a1 is necessary and/or sufficient for striosome development. We report that in vivo and in vitro, Nr4a1 and Oprm1 mRNA levels are correlated. In the absence of $\mathrm{Nr} 4 \mathrm{a}$, there is a decrease in the percentage of striatal surface area occupied by striosomes. Alterations in Nr4a1 expression leads to dysregulation of multiple mRNAs of members of the dopamine receptor $\mathrm{D}_{1}$ signal transduction system. Constitutive overexpression of $\mathrm{Nr} 4 \mathrm{a} 1$ decreases both the induction of phosphorylation of ERK after a single cocaine exposure and locomotor sensitization following chronic cocaine exposure. Nr4a1 overexpression increases MSN excitability but reduces MSN long-term potentiation. In the resting state, type 5 adenylyl cyclase (AC5) activity is normal, but the ability of AC5 to be activated by Drd1 G-protein-coupled receptor inputs is decreased. Our results support a role for Nr4a1 in determination of striatal patch/matrix structure and in regulation of dopaminoceptive neuronal function.
\end{abstract}

Key words: dopamine receptor $\mathrm{D}_{1}$; ERK; Nr4a1; signal; striosome; transduction

\section{Significance Statement}

This study provides insight into the role of $\mathrm{Nr4a1}$, a transcription factor belonging to the family of orphan nuclear receptors Nurr, in the development of the striatal striosomal compartment and in the regulation of dopaminoceptive neuronal function. We show that the alteration of Nr4a1 expression impacts the expression of striosome markers in vivo and in vitro, suggesting that Nr4a1 is necessary for full striosome development. Moreover, Nr4a1 overexpression alters Drd1 signal transduction at multiple levels, resulting in reduced phosphorylation of ERK after cocaine administration, reduced induction of LTP, and the absence of locomotor sensitization following chronic cocaine use. These results indicate that the pathways regulated by Nr4a1 may represent novel, druggable approaches to pathologic states such as levodopa-induced dyskinesia and cocaine sensitization. 


\section{Introduction}

The dorsal striatum is a subcortical nucleus with a role in the regulation of movement, reward, and cognition. More than $90 \%$ of the striatal neurons are GABAergic medium-sized spiny projecting neurons (MSNs) and are dopaminoceptive. They are subclassified as direct MSNs (dMSNs), expressing the dopamine (DA) $D_{1}$ receptor $\left(D_{1} R\right)$ and projecting to the substantia nigra (SN), or indirect MSNs (iMSNs), expressing the dopamine $D_{2}$ receptor and projecting to the globus pallidus. In addition, MSNs may be divided into patch (i.e. striosomes) or matrix compartments (Crittenden and Graybiel, 2011; Brimblecombe and Cragg, 2017). The striosomes comprise $10-15 \%$ of the striatal volume, receive limbic inputs, and contain both direct and indirect MSNs, with current data indicating a preponderance of dMSNs (Miyamoto et al., 2018). The transcription factor Nr4a1, called Nurr77, is an orphan member of the Nurr family of steroid/thyroid-like receptors (Giguère, 1999), appears as early as embryonic day 14.5 (E14.5) in the mouse, and marks striosomal MSNs (Davis and Puhl, 2011). Other striosomal markers include the $\mu$-opioid receptor 1 [Oprm1/MOR ( $\mu$-opioid receptors)], substance $\mathrm{P}$ (Tac1), and calretinin fibers. Matrix MSNs express calbindin (Calb1), somatostatin (Sst), and enkephalin (Penk; Crittenden and Graybiel, 2011).

Nr4a1 is expressed in dopaminergic and dopaminoceptive neurons, including in the dorsal striatum, nucleus accumbens, olfactory tubercle, and prefrontal and cingulate cortex (Zetterström et al., 1996; Beaudry et al., 2000; Werme et al., 2000a); and at lower levels, in SN and ventral tegmental area (VTA). Dopamine receptor antagonists, psychostimulants, or DA denervation induce the expression of Nr4a1 in the midbrain dopaminergic SN and VTA and increase its expression in the striatum, where it acts as an immediate early gene (IEG; Beaudry et al., 2000; Werme et al., 2000a,b; St-Hilaire et al., 2003a; Ethier et al., 2004). Murine Nr4a1 genetic deletion is associated with an increase in tyrosine hydroxylase, dopamine turnover (Gilbert et al., 2006), baseline locomotor activity (Gilbert et al., 2006; Rouillard et al., 2018), and tardive dyskinesia (Ethier et al., 2004), but a reduction in levodopa induces dyskinesia [levodopa-induced dyskine-

Received August 2, 2019; accepted August 29, 2019; First published September 20, 2019.

The authors declare no competing financial interests.

Author contributions: M.-D.C., C.M., T.F., S.N., K.A.M., J.L.P., L.M.E., and M.E.E. designed research; M.-D.C., C.M., T.F., S.N., K.-T.T., and B.S.M. performed research; M.-D.C., C.M., T.F., S.N., K.-T.T., B.S.M., K.A.M., and J.L.P. analyzed data; M.-D.C., B.S.M., K.A.M., J.L.P., L.M.E., and M.E.E. wrote the paper.

This research was supported by the Collaborative Center for X-linked Dystonia Parkinsonism; and by Department of Health and Human Services I National Institutes of Health I National Institute of Neurological Disorders and Stroke Grant R01-NS-100529 (to L.M.E. and M.E.E.).

${ }^{*}$ M.D.C. and C.M. contributed equally to this work.

Correspondence should be addressed to Michelle E. Ehrlich at Michelle.ehrlich@mssm.edu.

https://doi.org/10.1523/ENEURO.0305-19.2019

Copyright (C) 2019 Cirnaru et al.

This is an open-access article distributed under the terms of the Creative Commons Attribution 4.0 International license, which permits unrestricted use, distribution and reproduction in any medium provided that the original work is properly attributed. sia (LID)] in both rodent and nonhuman primate models of Parkinson's disease (St-Hilaire et al., 2003a,b; Mahmoudi et al., 2009, 2013).

We began our studies in the Nr4a1-eGFP mouse (\#GY139Gsat/Mmucd, GENSAT) to assay dopamine signal transduction in the striosomes, but found that the responses of these mice to dopamine agonists differed from those of nontransgenic littermates. We determined that the baseline Nr4a1 mRNA level in this line is twice the wild-type (WT) level. Herein, comparing the Nr4a1-eGFP mouse to the previously characterized Nr4a1-null mouse (Lee et al., 1995), we sought to determine the role of Nr4a1 in striosome development and regulation of the physiology of MSNs, and the dopamine signal transduction pathway. Our data indicate that Nr4a1 is necessary for, and promotes, the complete maturation of the striosome compartment, and its constitutive overexpression alters the $D_{1} R$ signaling pathway and response to cocaine.

\section{Materials and Methods}

\section{Animals}

Animal procedures were conducted in accordance with the NIH Guidelines for the Care and Use of Experimental Animals and were approved by the Institutional Animal Care Committee. The Nr4a1-eGFP hemizygous, Nr4a1null (JAX Nr4a1tm1Jm \#006187), Drd1-eGFP [Tg(Drd1aeGFP)X60Gsat], and Drd1 tdTomato (catalog \#016204, The Jackson Laboratory) mice used for this study were obtained from GENSAT and The Jackson Laboratory, respectively. Controls always consisted of wild-type littermates. Mice were given ad libitum access to food and water and housed under a $12 \mathrm{~h}$ light/dark cycle. Only male mice were used in these studies.

\section{Drugs and treatment}

Cocaine (20 mg/kg, i.p.) and MK-801 (0.1 mg/kg, i.p.; Sigma-Aldrich) were dissolved in $0.9 \%(\mathrm{w} / \mathrm{v}) \mathrm{NaCl}$ (saline). Mice were habituated to handling and saline injection for 3 consecutive days before the experiment. Drugs were administered on day 4 . MK-801 was administered 30 min before the cocaine injection.

\section{Locomotor activity}

Locomotor activity was measured using the Digiscan D-Micropro automated activity monitoring system (Accuscan), consisting of transparent plastic boxes $(45 \times 20$ $\times 20$ ) set inside metal frames that were equipped with 16 infrared light emitters and detectors with 16 parallel infrared photocell beams. The breaks were recorded by a computer interface in $5 \mathrm{~min}$ bins. Mice were injected with cocaine (20 mg/kg, i.p.) or saline (3 ml/kg, i.p.) for 5 consecutive days. On days 1 and 5 , mice were placed into the boxes and activity was recorded for 60 min during acclimation to the chamber. After $60 \mathrm{~min}$, cocaine or saline was administered, and mice were immediately returned to the boxes for an additional 60 min of recording.

\section{Tissue preparation and immunofluorescence}

At 4 months, mice were anesthetized with pentobarbital (30 mg/kg, i.p.) and transcardially perfused with ice-cold 
$0.1 \mathrm{~m}$ PBS, pH 7.5 (PBS $1 \times$ ) and 4\% (w/v) paraformaldehyde (PFA). Brains were postfixed overnight in the same solution and stored at $4^{\circ} \mathrm{C}$ in PBS. The $30 \mu \mathrm{m}$ serial coronal free-floating sections were cut on a Leica vibratome, collected in cryobuffer $(30 \%$ ethylene glycol, $20 \%$ glycerol in PBS $1 \times, \mathrm{pH} 7.4$ ) and stored at $4^{\circ} \mathrm{C}$.

Postnatal day 3 (P3) mice were rapidly killed by decapitation, and brains were removed, washed in ice-cold PBS, and postfixed for $24 \mathrm{~h}$ at $4^{\circ} \mathrm{C}$ in $4 \%$ PFA. The brains were then incubated in 30\% sucrose/1× PBS for $24 \mathrm{~h}$ at $4^{\circ} \mathrm{C}$ and cryopreserved in OCT embedding medium (catalog \#4583, Tissue-Tek, Sakura). Serial coronal section $(16 \mu \mathrm{m})$ were cut on a Leica cryostat, collected on Superfrost Plus Microscope Slides (Thermo Fisher Scientific), and frozen at $-20^{\circ} \mathrm{C}$.

Immunofluorescence was performed as previously described (Keilani et al., 2012). Sections were incubated with rabbit anti-phospho-p44/42 MAPK (ERK 1/2; Thr202/ Tyr204; 1:500; catalog \#9101S, Cell Signaling Technology), goat anti-c-fos (1:500, catalog \#sc-52-G, Santa Cruz Biotechnology), rabbit anti-DARPP-32 (1:250; catalog \#2306S, Cell Signaling Technology), mouse anti-calbindin 1 (1:500; catalog \#C9848-2ml, Millipore-Sigma), or rabbit anti-MOR (1:1000; catalog \#24216, Immunostar) antibodies. The respective secondary antibodies used were as follows: anti-mouse Alexa Fluor 488 (1:400; catalog \#A11008, Thermo Fisher Scientific), anti-mouse Alexa Fluor 594 (1:400; catalog \#A-11005, Thermo Fisher Scientific), anti-rabbit Alexa Fluor 488 (1:400; catalog \#A-11034, Thermo Fisher Scientific), or anti-rabbit Alexa Fluor 594 (1:400; catalog \#A-11012, Thermo Fisher Scientific). Sections were sealed with Vectashield hard set mounting medium (catalog \#H-1400, Vector Laboratories). Images were acquired using an Olympus BX61 epifluorescence microscope or a Panoramic 250 digital scanner (3DHISTECH) using a motorized $40 \times$ objective and a fluorescent camera. Quantification for the microscopy experiments was performed using slide scanner images except for the quantification of the striosomal area and the number for which both BX61 and slide scanner images were used.

\section{Striosome quantification}

Striosome number and area, as a percentage of total striatal area, were measured in coronal sections from either matched adult or P3 mice immunolabeled with anti-MOR or anti DARPP-32, respectively. Using Fiji (version 2.0.0), the images were set at identical thresholds, and the regions of interest (ROIs) were outlined by manual tracing and managed with $\mathrm{ROI}$ manager function. The area and number of the ROls selected were calculated using the Fiji "measure" function.

\section{Cell counting}

The induction of phosphorylated ERK ( $p E R K$ ) differs by region, so the numbers of $\mathrm{pERK}$ and $\mathrm{c}$-fos cells were counted specifically in the dorsomedial area of the striatum at rostral $+1.18 \mathrm{~mm}$, relative to bregma, and at caudal $0.86 \mathrm{~mm}$. Cells were quantified in a fixed area using CaseViewer software by an observer blinded to treatment.
To determine the number and percentage of Drd1, Nr4a1-eGFP, and Drd2 cells in striosomes, we used coronal sections from double-hemizygous Nr4a1-eGFP/ Drd1-Tomato (Shuen et al., 2008) at bregma $0.86 \mathrm{~mm}$. The striosomal area was outlined by manual tracing, and the cells were counted as $\mathrm{GFP}^{+}$, Tomato ${ }^{+}$, and GFP/ Tomato $^{+}$. The percentage of each population was calculated relative to the total number of cells indicated by 4[prime],6[prime]-diamidino-2-phenylindole dihydrochloride (DAPI) staining.

\section{Primary neuronal cultures}

Nr4a1-eGFP hemizygous and WT mice were timed mated, and the striatum was removed from E16.5 embryos by microdissection in cold Invitrogen Leibovitz's medium ( $L-15$, Thermo Fisher Scientific). The tissue was incubated in $\mathrm{Ca}^{2+} / \mathrm{Mg}^{2+}$-free HBSS for 10 min at $37^{\circ} \mathrm{C}$. The incubation mixture was replaced with $0.1 \mathrm{mg} / \mathrm{ml} \mathrm{pa-}$ pain in Hibernate $\mathrm{E} / \mathrm{Ca}^{2+}$ (BrainBits), incubated for $8 \mathrm{~min}$, and rinsed in DMEM with $20 \%$ fetal bovine serum and twice in Leibovitz's medium ( $L-15)$. The tissue was then suspended in DMEM with $10 \%$ fetal calf serum, glucose $(6 \mathrm{mg} / \mathrm{ml})$, glutamine $(1.4 \mathrm{mM})$, and penicillin/streptomycin $(100 \mathrm{U} / \mathrm{ml})$. Cells were triturated through a glass-bore pipette and plated onto either Lab Tek eight-well slides (125,000 cells/well) for immunocytochemistry or 24-well plates $\left(1 \times 10^{6}\right.$ cells/well) for RT-PCR analysis, each previously coated with polymerized polyornithine $(0.1$ $\mathrm{mg} / \mathrm{ml}$ in $15 \mathrm{~mm}$ borate buffer, $\mathrm{pH}$ 8.4) and air dried. One hour later, the media were replaced with Invitrogen Neurobasal/B27 medium (Thermo Fisher Scientific) with GLUTAMAX and penicillin/streptomycin, and select wells were treated with brain-derived neurotrophic factor (BDNF; catalog \#248-BD, R\&D Systems) $25 \mathrm{ng} / \mathrm{ml}$ in $0.1 \% \mathrm{BSA} / 1 \times$ PBS. Media change and BDNF treatment were performed every $2 \mathrm{~d}$, and the cells were kept in culture until day in vitro 7 (DIV7).

\section{Nr4a1-eGFP adenovirus transduction}

Adenovirus (ADV)-CMV-Nr4a1-eGFP and ADV-CMVeGFP were produced by SignaGen Laboratories. Nr4a1eGFP ADV was produced using the human Nr4a1 cDNA sequence. Viral transduction was performed after cells had attached for $48 \mathrm{~h}$ with a multiplicity of infection (MOI) of 20. The virus was added in fresh medium, and the medium was changed $18 \mathrm{~h}$ later. Cells were harvested or fixed $96 \mathrm{~h}$ following the addition of virus. ADV transduction in primary neurons was performed in four independent sets of cultures.

\section{Human induced pluripotent stem cell-derived NSC culture, differentiation, and transduction}

Human induced pluripotent stem cells (iPSCs) were differentiated into prepatterned Activin A-treated neural stem cells (NSCs) using the following protocol. Briefly, iPSC colonies were detached using $1 \mathrm{mg} / \mathrm{ml}$ collagenase in Gibco KnockOut DMEM/F-12 medium (Thermo Fisher Scientific), and the resulting cell clumps were transferred to a $0.1 \%$ agarose-coated low-attachment Petri dish in embryonic stem (ES) culture medium [Gibco KnockOut DMEM/F12 (Thermo Fisher Scientific) supplemented with 
Table 1. qRT-PCR primers sequence

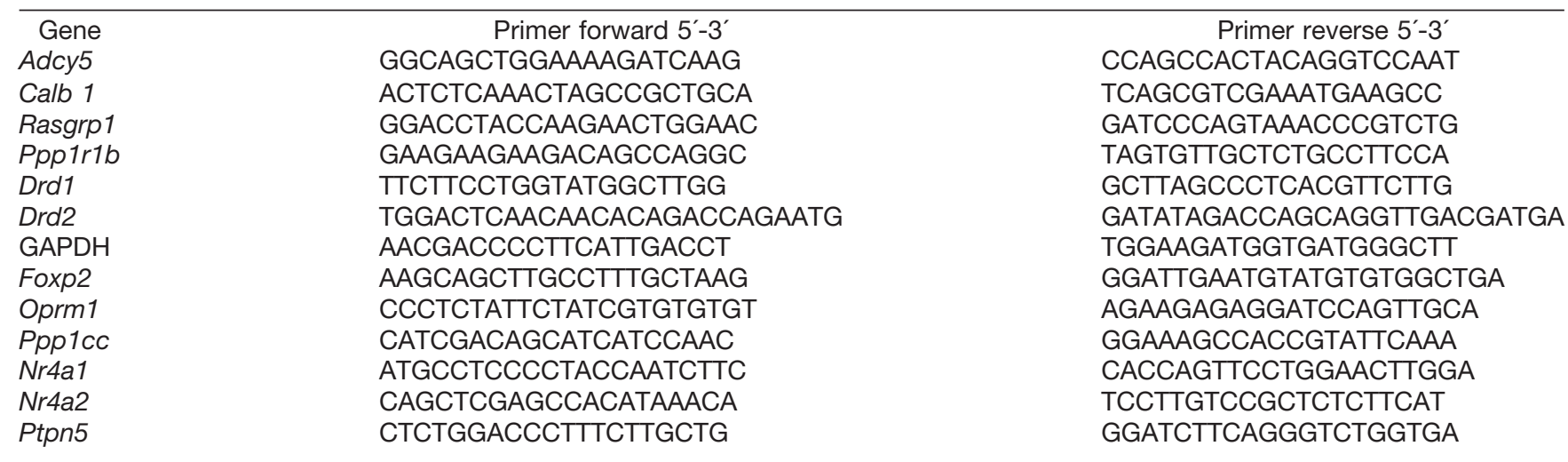

20\% Gibco KnockOut Serum Replacement (Thermo Fisher Scientific), $2.5 \mathrm{~mm}$ L-glutamine, $1 \times$ Non-Essential Amino Acids (NEAAs), $15 \mathrm{~mm}$ HEPES, $0.1 \mathrm{~mm}$ $\beta$-mercaptoethanol, $100 \mathrm{U} / \mathrm{ml}$ penicillin, $100 \mu \mathrm{g} / \mathrm{ml}$ streptomycin]. Every $2 \mathrm{~d}, 25 \%$ of ES medium was replaced by embryoid body (EB) differentiation medium (DMEM supplemented with $20 \%$ FBS, $1 \times$ NEAA, 2 mM L-glutamine, $100 \mathrm{U} / \mathrm{ml}$ penicillin, and $100 \mu \mathrm{g} / \mathrm{ml}$ streptomycin). At day $8,100 \%$ of the culture medium was EB medium. At day 10 , the embryoid bodies were attached to dishes coated with poly-L-ornithine (1:1000 in PBS; catalog \#P3655, Sigma-Aldrich) and laminin (1:100 in KnockOut DMEM/F12; catalog \#L2020, Sigma-Aldrich), and cultured in neural induction medium [DMEM/F12 supplemented with $1 \times \mathrm{N} 2$ (Thermo Fisher Scientific), $100 \mathrm{U} / \mathrm{ml}$ penicillin, and 100 $\mu \mathrm{g} / \mathrm{ml}$ streptomycin] and $25 \mathrm{ng} / \mathrm{ml}$ bFGF (Peprotech) and $25 \mathrm{ng} / \mathrm{ml}$ Activin A (Peprotech). Media change was performed every $2 \mathrm{~d}$. Rosettes were harvested after 7-10 s, plated on poly-L-ornithine- and laminin-coated dishes, and cultured in Neural Proliferation Medium (NPM; Neurobasal medium, $1 \times$ Gibco B27-supplement [Thermo Fisher Scientific), $2 \mathrm{~mm}$ L-glutamine, $10 \mathrm{ng} / \mathrm{ml}$ leukemia inhibitory factor (catalog \#300-05, Peprotech), $100 \mathrm{U} / \mathrm{ml}$ penicillin, $100 \mu \mathrm{g} / \mathrm{ml}$ streptomycin] supplemented with 25 $\mathrm{ng} / \mathrm{ml} \mathrm{bFGF}$ and $25 \mathrm{ng} / \mathrm{ml}$ Activin A. The resulting NSCs were passaged and maintained in this same medium. These prepatterned Activin A-treated NSCs were validated by immunofluorescence analysis and labeled positively for putative NSC markers, namely Nestin, SOX1, SOX2, and PAX6.

For the ADV transduction experiments human iPSCderived NSCs were plated at 100,000 cells per well of a 6-well plate in $2 \mathrm{ml}$ NPM supplemented with $10 \mathrm{ng} / \mathrm{ml}$ FGF2 (Peprotech) and $10 \mathrm{ng} / \mathrm{ml}$ Activin A (Peprotech). At $70 \%$ confluency, they were transduced with ADV-CMVNR4A1-eGFP or ADV-CMV-eGFP at MOI of 20 suspended in $2 \mathrm{ml}$ NPM without penicillin/streptomycin antibiotic. Nontransduced NSCs and NSCs transduced with ADV-eGFP were used as controls. A complete media change was performed $24 \mathrm{~h}$ post-transduction. Cells were harvested $14 \mathrm{~d}$ after transduction for gene expression and immunolabeling assays. ADV transduction in a human iPSC-derived NSC culture was performed twice, with three replicates each.

\section{Cell immunofluorescence}

Cultures were fixed in $4 \%$ paraformaldehyde in $0.1 \mathrm{M}$ phosphate buffer, $\mathrm{pH} 7.4$, and immunolabeled with rabbit anti-DARPP-32 (1:500; catalog \#2306S, Cell Signaling Technology) followed by anti-rabbit Alexa Fluor 594 (1: 400; catalog \#A-11012, Thermo Fisher Scientific). To identify the total number of cells, the nuclei were stained with DAPI (1:10,000; Millipore-Sigma). Images were acquired using an Olympus BX61 microscope and were analyzed using Fiji software (ImageJ).

\section{Quantitative real-time PCR}

Snap-frozen samples for gene expression assays were homogenized in QIAzol Lysis Reagent (Qiagen). Total RNA was extracted with the miRNeasy Mini Kit (Qiagen) according to the manufacturer instructions. RNAs, 500 ng, were reversed transcribed using the High Capacity RNA-to-cDNA Kit (Applied Biosystems). Quantitative realtime PCR (qRT-PCR) was performed in a Step-One Plus System (Applied Biosystems) using All-in-One qPCR Mix (GeneCopoeia).

For qRT-PCR analysis of prepatterned Activin A-treated human NSCs, total RNA was isolated using the ISOLATE II RNA Mini Kit (Bioline). cDNA was prepared from $1 \mu \mathrm{g}$ of RNA in a total reaction volume of $20 \mu \mathrm{l}$ using the SensiFAST cDNA synthesis kit (Bioline). RT-PCR reactions were set up in a 384-well format using $2 \times$ SensiFAST Probe No-ROX Kit (Bioline) and $1 \mu \mathrm{l}$ of cDNA per reaction in a total volume of $10 \mu \mathrm{l}$. RT-PCR was performed on the Roche LightCycler 480 instrument.

Quantitative PCR consisted of 40 cycles, $15 \mathrm{~s}$ at $95^{\circ} \mathrm{C}$ and $30 \mathrm{~s}$ at $60^{\circ} \mathrm{C}$ each, followed by dissociation curve analysis. The $\Delta \mathrm{Ct}$ was calculated by subtracting the $\mathrm{Ct}$ for the endogenous control gene GAPDH from the $\mathrm{Ct}$ of the gene of interest. Mouse and human primer sequences are listed in Table 1 and in Table 2, respectively. Relative quantification was performed using the $\Delta \Delta \mathrm{Ct}$ method (Livak and Schmittgen, 2001) and is expressed as a fold change relative to control by calculating $2^{-\Delta \Delta \mathrm{Ct}}$.

\section{Western blotting}

Snap-frozen striatum samples dissected from Nr4a1eGFP, Nr4a1-null, and WT mice were lysed in Pierce RIPA buffer (Thermo Fisher Scientific) containing freshly added 
Table 2. qRT-PCR human primer sequences

\begin{tabular}{llr}
\hline Gene & Primer forward $5^{\prime}-3^{\prime}$ & Primer reverse $5^{\prime}-3^{\prime}$ \\
Ppp $1 r 1 b$ & CACACCACCTTCGCTGAAA & GAAGCTCCCCCAGCTCAT \\
Oprm1 & AGAAACAGCAGGAGCTGTGG & ACCGAGACTTTTCGGGTTC \\
Calb2 & GAAAATCGAGATGGCAGAGC & CATAAACTCGGCGCTGGA \\
Calb1 & CACAGCCTCACAGTTTTCG & CCTTCCTTCCAGGTAACCA \\
B $111 b$ & CCCAGAGGGAGCTCATCAC & GACACTGGCCACAGGTGAG \\
ACTB & CCAACCGCGAGAAGATGA & TCCATCACGATGCCAGTG \\
\hline
\end{tabular}

Pierce phosphatase and protease inhibitors (Thermo Fisher Scientific). The supernatant was collected after centrifugation $\left(20 \mathrm{~min}\right.$ at $15,000 \times g$ at $4^{\circ} \mathrm{C}$ ), and the protein concentration was determined using the BCA method. For each sample, $30 \mu \mathrm{g}$ of protein was resolved in $4-12 \%$ Bis/Tris-acrylamide gradient gels (Bio-Rad) and transferred to nitrocellulose membranes. The membranes were incubated with the following primary antibodies: rabbit anti-ERK1/2 (1:500; catalog \#9102, Cell Signaling Technology), mouse anti-AC5 (type 5 adenylyl cyclase; Xie et al., 2015), and mouse anti-GAPDH (1:5000; catalog \#sc32233, Santa Cruz Biotechnology) for the normalization. The following secondary antibodies were used: antirabbit HRP-conjugated (1:2000; catalog \#PI-1000, Vector Laboratories) or anti-mouse HRP-conjugated (1:2000; catalog \#PI-2000, Vector Laboratories). Following development with Pierce ECL (Thermo Fisher Scientific), pictures were acquired using a Fujifilm ImageReader LAS4000, and bands were quantified using Fiji software (ImageJ).

\section{Patch-clamp recordings}

Patch-clamp whole-cell recordings were performed from the dorsal striatum of the $300-\mu \mathrm{m}$-thick coronal brain slices obtained from 4-month-old mice. An upright microscope with differential interference contrast, fluorescence, and IR (Nikon Eclipse E600FN, Morrel Instrument) was used to visualize the neurons. The cells were voltage clamped at $-70 \mathrm{mV}$, using patch pipettes (resistance, 3-6 $\mathrm{M} \Omega$ ) filled with an internal solution containing the following (in $\mathrm{mm}$ ): $115 \mathrm{~K}$-gluconate, $20 \mathrm{NaCl}, 1.5 \mathrm{MgCl} 2,10$ phosphocreatine-Tris, $2 \mathrm{Mg}$-ATP, $0.5 \mathrm{Na}-\mathrm{GTP}$, and 10 HEPES, pH 7.3 and $286 \mathrm{mmol} / \mathrm{kg}$ osmolarity. The hemislices were transferred to a recording chamber constantly perfused with oxygenated aCSF at a flow rate of $\sim 4$ $\mathrm{ml} / \mathrm{min}$ for gravity. Experiments were performed at $28.0 \pm$ $0.1^{\circ} \mathrm{C}$. Series resistance was monitored through the experiments, and cells with a $>10 \%$ change in series resistance were excluded from analysis. Recordings were acquired with a Multiclamp 700B Amplifier (Molecular Devices) and Digidata 1440A digitizer (Molecular Devices). Current-clamp protocols were designed and performed using pClamp 10.3 Electrophysiology Data Acquisition and Analysis Software. Output signals were acquired at $5 \mathrm{kHz}$, filtered at $2.4 \mathrm{kHz}$, and stored on-line using pCLAMP 10.3 Electrophysiology Data Acquisition and Analysis Software (Molecular Devices). Single-cell long-term depression (LTD) was induced in the presence of $10 \mu \mathrm{M} 1(\mathrm{~S}) 9(\mathrm{R})(-)$ bicuculline methiodide using a highfrequency stimulation (HFS) protocol (Calabresi et al., 1997) consisting of four 1 -s-duration, $100 \mathrm{~Hz}$ trains deliv- ered at a frequency of one train every $10 \mathrm{~s}$. Square-wave current pulses (60 $\mu$ s pulse width) were delivered with a concentric bipolar electrode placed above the corpus callosum through a stimulus isolator (Isoflex, AMPI). Output signals were acquired at $5 \mathrm{kHz}$, filtered at $2.4 \mathrm{kHz}$, and stored on-line using pCLAM 10.3Electrophysiology Data Acquisition and Analysis Software (Molecular Devices). In all cases, the experimenter was blind to genotype and or/treatment.

\section{Field electrophysiology}

Coronal brain slices containing the striatum were prepared from 9-week-old WT or Nr4a1-eGFP mice. Animals were anesthetized with isoflurane, and brains were rapidly removed from the skull and placed in ice-cold modified solution (aCSF) containing the following (in $\mathrm{mm}$ ): 215 sucrose, $2.5 \mathrm{KCl}, 1.6 \mathrm{NaH}_{2} \mathrm{PO}_{4}, 4 \mathrm{MgSO} 4,1 \mathrm{CaCl}, 4$ $\mathrm{MgCl}$, 20 glucose, and $26 \mathrm{NaHCO}, \mathrm{pH} 7.4$, and equilibrated with $95 \% \mathrm{O}_{2}$ and $5 \% \mathrm{CO}_{2}$. Coronal brain slices (250 $\mu \mathrm{m}$ thick) were prepared with a VT1000S Vibratome (Leica Microsystems), incubated at $31^{\circ} \mathrm{C}$ for $30 \mathrm{~min}$, and then stored at room temperature for $\geq 1 \mathrm{~h}$ in normal aCSF containing the following (in $\mathrm{mm}$ ): $120 \mathrm{NaCl}, 3.3 \mathrm{KCl}, 1.2$ $\mathrm{Na}_{2} \mathrm{HPO}_{4}, 26 \mathrm{NaHCO}$, 1.3 MgSO4, $1.8 \mathrm{CaCl}$, and 11 glucose, $\mathrm{pH} 7.4$ equilibrated with $95 \% \mathrm{O}_{2}$ and $5 \% \mathrm{CO}_{2}$, 280-300 $\mathrm{mmol} / \mathrm{kg}$ osmolarity. The hemi-slices were transferred to a recording chamber constantly perfused with oxygenated aCSF at a flow rate of $\sim 4 \mathrm{ml} / \mathrm{min}$ using a peristaltic pump (Masterflex C/L); experiments were performed at $28.0 \pm 0.1^{\circ} \mathrm{C}$. Recordings were acquired with a GeneClamp 500B Amplifier (Molecular Devices) and a Digidata 1440A digitizer (Molecular Devices). All signals were low-pass filtered at $2 \mathrm{kHz}$ and digitized at $10 \mathrm{kHz}$. For extracellular field recordings (fEPSP recordings), a patch-type pipette was fabricated on a micropipette puller (Sutter Instrument), filled with normal aCSF (resistance, 3-6 M $\Omega$ ), and placed in the dorsomedial striatum to measure long-term potentiation (LTP). A Concentric Bipolar Electrode stimulator (FHC) was placed immediately above the corpus callosum. Before and after HFS, the stimulus intensity was set to the level at which an evoked population spike was around half of the amplitude of the maximal obtainable response. Stimulus intensity was adjusted to a level evoking a maximal response during HFS. Stimulus intensity ranged from 0.3 to $1.2 \mathrm{~mA}$ (Partridge et al., 2000). Paired-pulse facilitation was measured by delivering two stimuli at 20,50, and 100 ms interstimulus intervals before HFS. Each interstimulus interval was repeated three times, and the resulting potentials were averaged. LTP was induced using an HFS protocol, as follows: four $1 \mathrm{~s}$ duration, $100 \mathrm{~Hz}$ trains delivered at a frequency of one 
train every $10 \mathrm{~s}$. Square-wave current pulses (60 $\mu$ s pulse width) were delivered through a stimulus isolator (Isoflex, AMPI). Stimulus intensity was adjusted to evoke a maximal response during HFS (Partridge et al., 2000; Kreitzer and Malenka, 2007).

\section{cAMP measurement and adenylyl cyclase activity assay}

Flash-frozen striatal tissue punches from adult Nr4a1eGFP and WT mice were homogenized in $250 \mu \mathrm{l} 0.1 \mathrm{~N}$ $\mathrm{HCl}$, centrifuged at $1000 \times g$ for $15 \mathrm{~min}$, and supernatants diluted 20 -fold for cAMP quantification using a cAMP enzyme immunoassay kit (cAMP Direct EIA) following the acetylated protocol (Enzo). The activity of adenylyl cyclase (AC) in striatal membrane preparations was determined as described previously (Xie et al., 2012). Briefly, striatal tissue punches were flash frozen in liquid nitrogen before homogenization in a buffer containing the following (in mM): HEPES, pH 8.0 (20); EDTA (1); $\mathrm{NaCl}$ (150); $\mathrm{MgCl}_{2}$ (2), dithiothreitol (1); and $1 \times$ complete protease inhibitor cocktail (Roche). After centrifugation at $1000 \times g$ for 15 min, the supernatant was subject to ultracentrifugation at 25,000 rpm for $35 \mathrm{~min}$ in a Beckman SW41 rotor over a $23 \% / 43 \%$ sucrose gradient. The plasma membrane fraction was isolated from the sucrose interface, and the concentration was determined using the Pierce $660 \mathrm{~nm}$ Protein Assay Reagent (Thermo Fisher Scientific). Striatal membranes (2 $\mu \mathrm{g} /$ reaction) were treated with vehicle (basal) or indicated stimulator for $10 \mathrm{~min}$ at $30^{\circ} \mathrm{C}$ in $\mathrm{AC}$ assay buffer (50 mM HEPES, pH 8.0; 0.6 mM EDTA; 100 $\mu \mathrm{g} / \mathrm{ml} \mathrm{BSA} ; 100 \mu \mathrm{M}$ 3-isobutyl-1-methylxanthine; $3 \mathrm{~mm}$ phosphoenolpyruvate potassium; $10 \mu \mathrm{g} / \mathrm{ml}$ pyruvate kinase; $5 \mathrm{~mm} \mathrm{MgCl}$; $10 \mu \mathrm{M}$ GTP; and $100 \mu \mathrm{M}$ ATP). Reactions were stopped by adding an equal volume of $0.2 \mathrm{~N}$ $\mathrm{HCl}$. The resulting cAMP in the sample was determined by cAMP Direct EIA kit.

\section{Statistics}

Statistical analysis was performed using GraphPad software version 6. One-way ANOVA followed by Sidak's multiple-comparisons test was performed for one-factor comparisons versus control. For $2 \times 2 \mathrm{com}$ parisons, two-way ANOVA was used with repeated measures for the appropriate factor followed by Bonferroni's or Holm-Sidak's post hoc comparisons. For the RT-PCR and Western blot densitometry, we performed one-way ANOVA with genotype factor analysis, followed by post hoc tests with multiple comparisons versus control or WT mice. To analyze locomotor data and AC5 activity results, two-way ANOVA with treatment and genotype factors were used. For the electrophysiology experiments, statistical comparisons of pooled data were performed by unpaired $t$ test or ANOVA (one-way or two-way). Results were considered significant at $p<0.05$. Values are presented as the mean \pm SEM based on the number of samples that were used in each experiment.

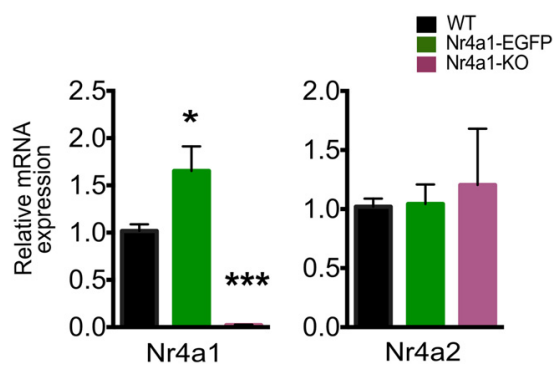

Figure 1. Nr4a1 mRNA is increased in Nr4a1-eGFP mice, and $\mathrm{Nr} 4 \mathrm{a} 2 \mathrm{mRNA}$ is equal to wild type. qRT-PCR expression analysis of Nr4a1 and Nr4a2 in 4-month-old WT, Nr4a1-eGFP, and Nr4a1-null mice. $n=6$ mice/genotype; one-way ANOVA corrected for multiple comparisons and Sidak's post-test with genotype factor. For Nr4a1 expression: $F_{(2,14)}=23.42, p<0.0001$; Nr4a2 expression: $F_{(2,20)}=0.1871, p=0.8308$. $* p=0.0145$, $* * * p=0.0010$. Data are presented as the mean \pm SEM.

\section{Results}

\section{Nr4a1 mRNA expression in Nr4a1-eGFP and Nr4a1- null mice}

Some GENSAT mice created using BAC technology [e.g. Drd2-eGFP (Kramer et al., 2011) and ChAT-Cre (Chen et al., 2018)] show expression from the transgene, increasing the total expression level of the BAC-encoded gene. Similarly, Nr4a1-eGFP adult hemizygous mice express twice as much $\mathrm{Nr} 4 a 1 \mathrm{mRNA}$ in the striatum relative to wild-type littermates (Fig. $1 ; F_{(2,14)}=23.42, p<0.0001$; Sidak's multiple-comparisons test, $t_{(14)}=2.787, p=$ 0.0145). The exact cause of Nr4a1 overexpression remains unknown. However, despite being engineered to prevent the increased levels of the reporter gene, several BAC mice show increased levels of the gene under study, or of other genes encoded on the BAC or impacted by insertion of the BAC (Kolisnyk et al., 2013; Ting and Feng, 2014). Confirming previous results (Lee et al., 1995), Nr4a1 mRNA expression is abolished in Nr4a1 homozygote-null [knock-out (KO)] mice (Fig.1; Sidak's multiple-comparisons test, $t_{(14)}=4.166, p=0.0010$ ). The level of mRNA of a second Nurr family member, Nr4a2, mRNA levels is unchanged in both genotypes (Fig. 1; $\left.F_{(2,20)}=0.1871, p=0.8308\right)$. We were unable to confirm the specificity of commercially available anti-Nr4a1 antibodies for immunocytochemistry or Western blotting.

\section{Nr4a1 striatal distribution and effect of its overexpression or deletion on striosome compartment maturation in vivo}

We analyzed several aspects of striatal phenotype in Nr4a1-eGFP and Nr4a1-null mice, including the compartmentalization of $\mathrm{EGFP}^{+}$neurons, the surface area occupied by striosomes; and the mRNA levels of striosome, matrix, and markers of common MSNs. Ppp1r1b/ DARPP-32 served as an early marker of striosomes, and as a general MSN marker in adult striatum. Calb1 (i.e. calbindin $28 \mathrm{kDa}$ ) was used as a marker of the matrix compartment, and Oprm1/MOR, Rasgrp1/Caldag-GEFII, and, to a lesser extent, Foxp2, as markers of striosomes in the adult (Crittenden et al., 2009; Crittenden and Graybiel, 2011). 
We quantitated the distribution of Nr4a1-eGFP, dMSNs, and iMSNs in the two compartments, using doublehemizygous Nr4a1-eGFP/Drd1-tdTomato adult mice (Fig. 2a). In the striosomes, we counted a total of 506 cells, of which $50 \%$ were tdTomato ${ }^{+}, 43 \% \mathrm{EGFP}^{+}$, and $23 \%$ were double labeled. In the matrix, from a total of 1362 cells, only $17.1 \%$ were $\mathrm{EGFP}^{+}$and only $5.8 \%$ were double labeled (Fig. 2b). Therefore, in the striosomes, assuming that the majority of Drd1-tdTomato ${ }^{-} / \mathrm{DAPI}^{+}$cells are $\mathrm{Drd} 2^{+}$, iMSNs and $\mathrm{dMSNs}$ are present at equal levels (i.e. $50 \%$ each). Focusing on Nr4a1 coexpression, $24 \%$ of the cells are $\mathrm{Drd}_{1}{ }^{+} / \mathrm{Nr}_{4 \mathrm{a}} 1^{+}$and $20 \%$ are $\mathrm{Drd} 2^{+} / \mathrm{Nr} 4 \mathrm{a} 1^{+}$(Fig. $2 \mathrm{c}$ ).

Nr4a1 overexpression in the GENSAT mouse does not alter the general architecture of the striatum as the area occupied by the striosomes is unchanged from the WT mouse at both P3 and in the adult (Fig. 2e; Sidak's multicomparisons test: adults, $t_{(15)}=0.1803, p=0.8593$; P3, $\left.t_{(19)}=0.3318, p=0.7437\right)$. Nr4a1 deletion, however, reduces the area occupied by striosomes at both $\mathrm{P} 3$ and 4 months, as determined by Oprm1 immunostaining (Fig. 2e; P3: $t_{(19)}=4.333, p=0.0004$; adults: $t_{(15)}=7.914, p=$ $0.0001)$. The number of striosomes is unchanged (Fig. $2 e$; $F_{(2,15)}=2.007, p=0.1689$; and $F_{(2,15)}=2.818, p=$ $0.0914)$. There is a positive correlation between $\mathrm{Nr} 4 \mathrm{a} 1$ and Oprm1 mRNA levels at both ages in the Nr4a1-eGFP mouse (Fig. 2f; $F_{(2,20)}=15.52, p<0.0001$ and $F_{(2,12)}=$ $8.711, p=0.0046$, respectively). Rasgrp1 mRNA level is increased at 4 months in the Nr4a1-eGFP mouse (Fig. 2f; Sidak's multicomparisons test: $t_{(11)}=4.082, p=0.0018$ ), and, relative to the WT mouse, decreased in the Nr4a1null mouse at P3 (Fig. 2f; $t_{(8)}=2.378, p=0.0447$ ) with a trend downward at 4 months (Fig. $2 f ; t_{(11)}=1.639, p=$ 0.1295). Calb1 mRNA level is decreased in the Nr4a1-null mouse at $\mathrm{P} 3\left(t_{(12)}=2.721, p=0.0186\right)$, but is normal in the adult $\left(t_{(11)}=1.377, p=0.1969\right)$.

\section{Nr4a1 promotes maturation of the medium spiny neuron in vitro}

Given that Nr4a1 overexpression increases the striatal level of Oprm1 mRNA relative to wild type in vivo, we investigated whether Nr4a1 overexpression impacts the maturation of MSNs in vitro. Lateral ganglionic eminence primary neuronal cultures from E16.5 Nr4a1-eGFP embryos, compared with cultures from wild-type mice, have higher levels of Ppp1r1b/DARPP-32 (Fig.3a; Sidak's multiple comparisons test, $\left.t_{(27)}=2.910, p=0.0072\right)$ and Oprm1 mRNAs (Fig. 3a; $t_{(13)}=3.338, p=0.0053$ ). BDNF promotes the maturation of MSNs and requires Egr-1 (Keilani et al., 2012). We found that the BDNF and Nr4a1 effects on the induction of DARPP-32 are additive (Fig 3a; $t_{(27)}=5.479, p=0.0001$; Fig. $\left.3 b\right)$ and that BDNF does not induce Nr4a1 mRNA ( $\left.t_{(15)}=1.448, p=1.682\right)$, implying the use of alternate signal transduction pathways. Importantly, EGFP fluorescence was visible in these cultures at the time of plating and Nr4a1 mRNA was already increased (Fig. 3b), indicating expression from the BAC transgene at this early age.

We also transduced E16.5 wild-type MSNs in vitro with adenovirus driving expression from the human Nr4a1 cDNA (ADV-CMV-Nr4a1). Similar to constitutive overex- pression, exogenous Nr4a1 induced higher levels of Ppp1r1b (Fig. 3 c,d; unpaired two-tailed $t$ test, $t_{(6)}=2.551$, $p=0.0434$ ) and Oprm1 mRNAs (Fig. $3 d ; t_{(6)}=5.505, p=$ $0.0015)$ compared with transduction with ADV-CMV-GFP (Fig. $3 c, d$ ). Finally, we assayed the ability of Nr4a1 to induce the expression of MSN markers in human iPSCderived neuronal precursors. For this, we analyzed the expression of striatal markers in ADV-CMV-Nr4a1- versus ADV-CMV-GFP-transduced human iNSCs at $14 \mathrm{~d}$ of differentiation. Nr4a1 induced the expression of neuronal marker $\beta 3$ tubulin (Fig. 4a), of immature striosomespecific marker DARPP-32 (Ppp1r1b; $t_{(6)}=3.691, p=$ $0.0102)$, and of OPRM1 $\left(t_{(6)}=3.234, p=0.0178\right)$ and calretinin (Calb2; $t_{(6)}=5.461, p=0.0016$; Fig. 4b). Moreover, Nr4a1 overexpression also induced calbindin $\left(\right.$ Calb1; $\left.t_{(5)}=11.63, p=0.0001\right)$ and $\left(B c / 11 b ; t_{(6)}=4.848\right.$, $p=0.0029$ ), indicating that in this system Nr4a1 promotes the differentiation of NSCs toward both the MSN striosome and matrix phenotypes.

\section{Nr4a1 overexpression reduces induction of pERK and $c$-Fos after acute cocaine exposure and impairs locomotor sensitization to chronic cocaine}

LID induction following dopamine denervation of the striatum correlates with a high level of pERK (Santini et al., 2007; Westin et al., 2007; Alcacer et al., 2012; Cerovic et al., 2015) and requires a specific subpopulation of dMSNs (Girasole et al., 2018). Strikingly, LID is reduced in the absence of Nr4a1 (Rouillard et al., 2018), raising the question of whether $\mathrm{Nr} 4 \mathrm{a} 1$ level regulates acute induction of pERK. Relative to WT, the overexpression or deletion of Nr4a1 both decreased the induction of pERK 10 min after intraperitoneal cocaine administration, although the decrease was not significant in the null mouse (Fig. 5a,b; $F_{(2,8)}=7.281, p=0.0158$; Bonferroni's multiplecomparisons test: Nr4a1-eGFP mice: $t_{(8)}=3.816, p=$ 0.0051; Nr4a1-null mice: $\left.t_{(8)}=1.726, p=0.1226\right)$. The number of $\mathrm{pERK}^{+}$cells in saline-injected mice ranged from 7 to 10 in each genotype, similar to what is shown in the study by Valjent et al. (2004). Total ERK levels were unaltered (Fig. $5 c ; F_{(2,9)}=1.340, p=0.3094$ ). Comparisons among nontransgenic (WT), Drd1-eGFP, and Nr4a1eGFP mice demonstrated equal pERK induction in WT versus Drd1-eGFP mice $\left(F_{(2,9)}=1.584, p=0.2574\right.$; data not shown). The majority of $\mathrm{pERK}{ }^{+}$cells were located in the matrix (Fig. $5 d$ ), both in WT and Nr4a1-EGFP mice.

Additional experiments were restricted to the Nr4a1eGFP line. In Nr4a1-eGFP mice, c-fos induction $1 \mathrm{~h}$ after cocaine administration was reduced relative to Drd1eGFP and appeared to occur primarily in the striosomal compartment (Fig. 5e,f; two-tailed unpaired $t$ test, $t_{(4)}=$ 6.721, $p=0.0026$ ). Dopamine-mediated induction of pERK requires simultaneous activation of the $D_{1}$ and NMDA receptors (Valjent et al., 2005; Girault et al., 2007; Girault, 2012a,b). As in WT animals, pretreatment with MK-801 almost entirely abolished the induction of pERK in Nr4a1-eGFP mice (Fig. $5 g$ ).

Induction of pERK and c-fos after a single exposure to cocaine correlates with locomotor sensitization induced after chronic cocaine exposure, but not with acute loco- 
a

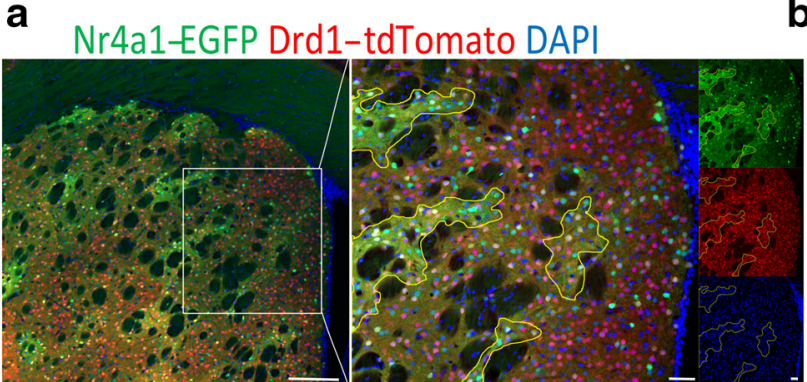

b

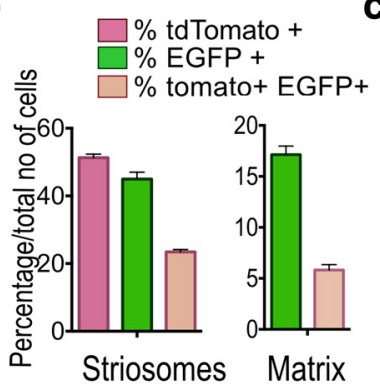

c

Drd1+ Nr4a1-

Drd1+ Nr4a1+

Drd2+ Nr4a1+

Drd2+ Nr4a1-

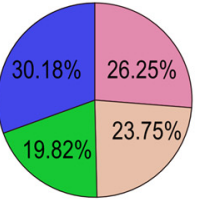

Striosomes d

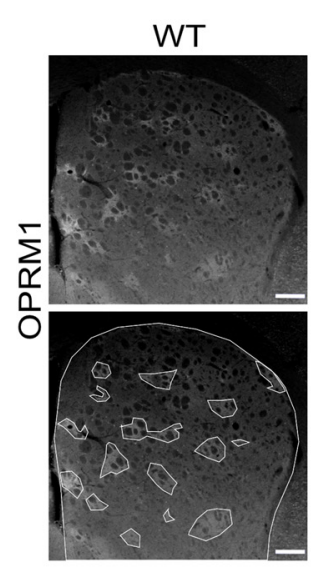

e
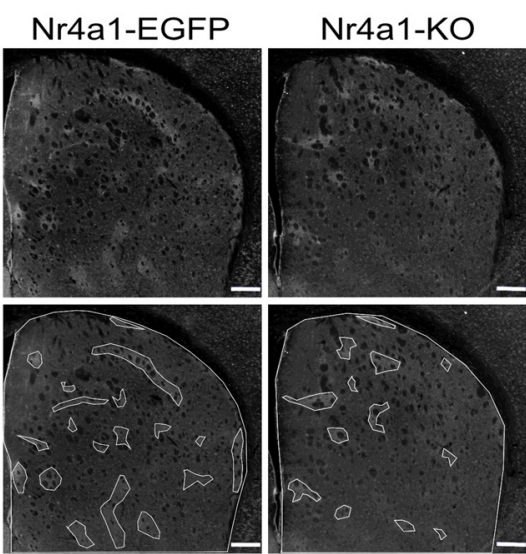
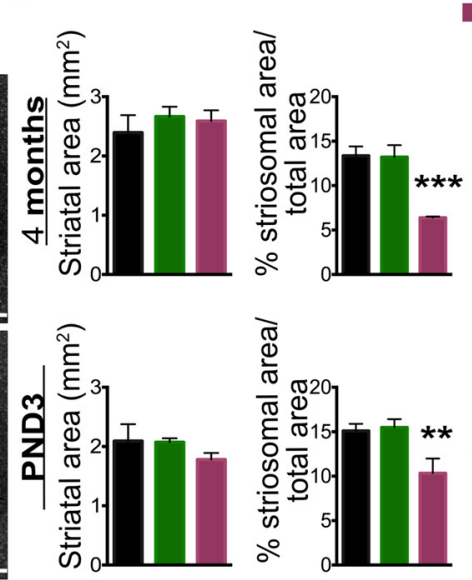

WT

Nr4a1-EGFP

- Nr4a1-KO

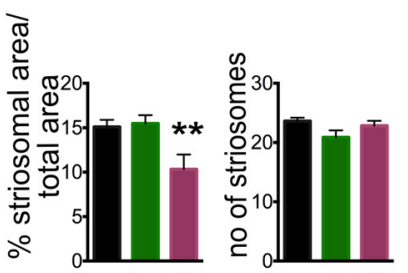

f
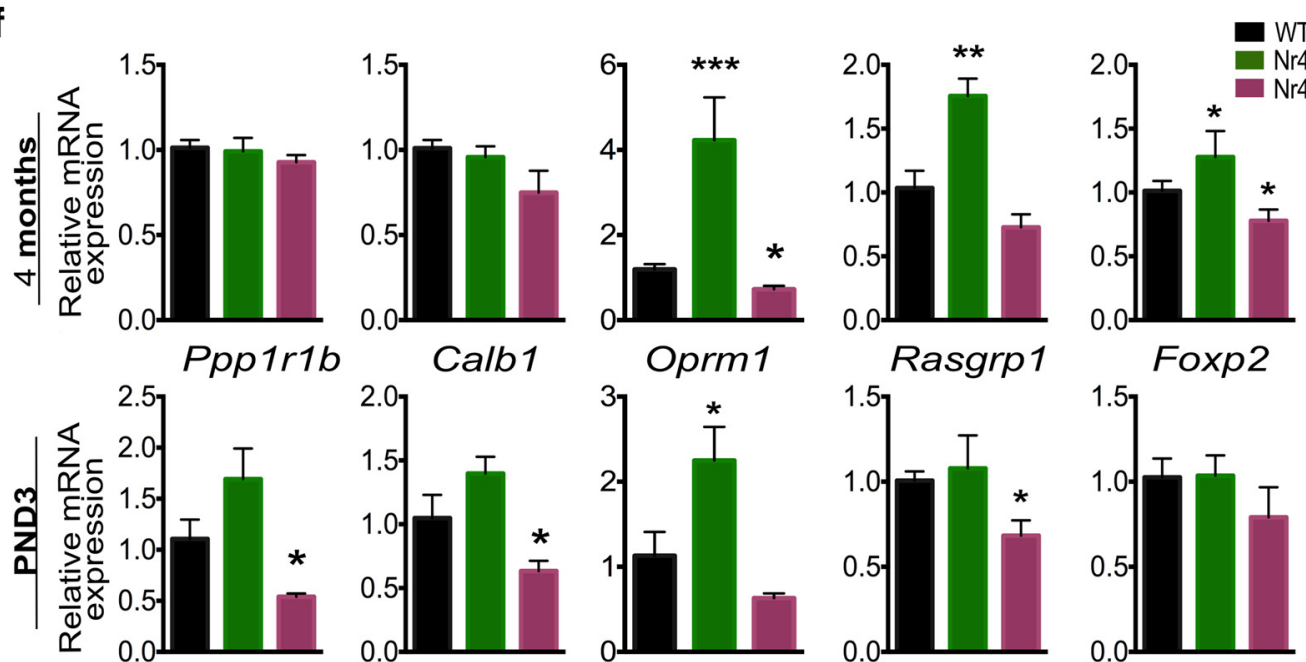

Figure 2. Constitutive upregulation or downregulation of Nr4a1 mRNA alters spatial development of the striosomal compartment and mRNA levels of its markers in vivo. a, Coronal section of adult Nr4a1-eGFP/Drd1-tdTomato showing the colocalization of Drd1tdTomato and Nr4a1-eGFP. The ROI selection indicates the section represented in higher magnification. Single channels are shown

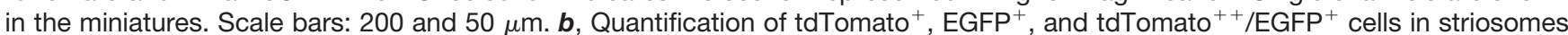
and matrix shown in $\mathbf{a}$. Percentage of each cell population was calculated relative to the total number of cells counted by DAPI immunofluorescence. c, Graphic representation of the percentage distribution of $\mathrm{Drd} 1^{+} \mathrm{O} / \mathrm{Nr} 4 \mathrm{a} 1^{-}, \mathrm{Drd} 1^{+} / \mathrm{Nr} 4 \mathrm{a} 1^{+}, \mathrm{Drd} 2^{+} / \mathrm{Nr} 4 \mathrm{a} 1^{+}, \mathrm{and}$ $\mathrm{Drd}^{+} / \mathrm{Nr} \mathrm{a} 1^{-}$in the striosomes. For this, the Drd1 (i.e., tdTomato ${ }^{-}$) cells were counted as Drd2 ${ }^{+}$cells. $\boldsymbol{d}$, Representative OPRM1 immunolabeling on 30- $\mu$ m-thick coronal sections from 4-month-old WT, Nr4a1-eGFP, and Nr4a1-null mice with superimposition of selected ROls delineating the total striatal and striosomal areas in the bottom panel. Scale bars, $200 \mu \mathrm{m}$. e, Quantification of the striatal area, the percentage of the area occupied by the striosomes, and of the number of striosomes in 4-month-old and P3 WT, Nr4a1-eGFP, and Nr4a1-null mice shows a decrease in the percentage of the area occupied by the striosomes in Nr4a1-null mice at both ages. For both P3 and adult analysis, $n=6$ mice/genotype. One-way ANOVA corrected for multiple comparisons (Sidak's test). For adults: striatal area $F_{(2,15)}=1.897, p=0.1943$; striosomal area: $F_{(2,15)}=40.83, p<0.0001$; WT vs Nr4a1-eGFP: $t_{(15)}=0.1803$, $p=0,8593$; WT vs Nr4a1-null: $t_{(15)}=7.914$, *** $p=0.0001$; number of striosomes: $F_{(2,15)}=2.007, p=0.1689$. For P3: striatal area: 
continued

$F_{(2,19)}=1,5481, p=0.2383 ;$ striosomal area: $F_{(2,19)}=12.87, p=0.0003 ;$ WT vs Nr4a1-eGFP: $t_{(19)}=0.3318, p=0.7437 ;$ WT vs Nr4a1-KO: $t_{(19)}=4.333, * * p=0.0004$; number of striosomes: $F_{(2,15)}=2.818, p=0.0914$. Data are presented as the mean \pm SEM. $\boldsymbol{f}$, mRNA levels of striosome and matrix marker as determined by qRT-PCR of striatal mRNA from 4-month-old and P3 WT, Nr4a1-eGFP, and Nr4a1-null mice reveals a positive correlation between Nr4a1 expression levels and striosomal markers Oprm1 $\left(F_{(2,20)}=15.52, p<0.0001\right.$; followed by Sidak's multiple-comparisons test vs WT: $t_{(20)}=4.732, p=0.0001$ for $N r 4 a 1-e G F P ; t_{(20)}=$ $1.099, p=0.2848$ for Nr4a1-KO), Rasgrp1 $\left(F_{(2,11)}=16.49, p=0.0005 ; t_{(11)}=4.082, p=0.0018 ; t_{(11)}=1.639, p=0.1295\right)$, and $F o x p 2$ $\left(F_{(2,11)}=20.02, p=0.0002 ; t_{(11)}=2.795, p=0.0174 ; t_{(11)}=3.174, p=0.0089\right)$ in the adult. In P3, Nr4a1-KO mice have reduced levels of Ppp1r1b $\left(F_{(2,15)}=13.96, p=0.0004 ; t_{(15)}=2.899, p=0.011\right)$, Calb1 $\left(F_{(2,12)}=10.77, p=0.0021 ; t_{(12)}=2.721, p=0.0186\right)$, and Rasgrp1 $\left(F_{(2,8)}=4.657, p=0.0456 ; t_{(8)}=2.378, p=0.0447\right) . n \geq 5$ mice/genotype, one-way ANOVA corrected for multiple comparisons (Sidak's test). $* p<0.05, * * p<0.01$, $* * * p<0.001$. Data are presented as the mean \pm SEM.

motor activity (Valjent et al., 2006; Xu, 2008). To assay acute locomotor response and sensitization, mice were injected for $5 \mathrm{~d}$ with cocaine $(20 \mathrm{mg} / \mathrm{kg}$, i.p.) or saline, and their locomotor activity was recorded for $60 \mathrm{~min}$ after the injections on days 1 and 5 (Fig. $5 h ; F_{(7,108)}=8.639, p<$ 0.0001). Nr4a1 overexpression did not alter the basal activity (Bonferroni's multiple-comparisons test, $t_{(108)}=$ $0.4087, p=0.6836$ ) or the locomotor response to the first injection of cocaine $\left(t_{(108)}=0.3489, p=0.7278\right)$, but, contrary to WT mice $\left(t_{(108)}=3.705, p=0.0003\right)$, the Nr4a1-eGFP mice did not sensitize $\left(t_{(108)}=0.6920, p=\right.$ 0.4904 ; i.e. did not show an increase in their locomotor response to cocaine on day 5 relative to day 1; Fig. 5i) while presenting normal locomotor activity without any sign of confined stereotypy due to repeat exposure to cocaine.

\section{Impact of $\mathbf{N r 4 a 1}$ overexpression on electrophysiological properties of dorsomedial striosomal MSNs and on striatal synaptic plasticity}

Altered dopaminergic transmission at corticostriatal synapses is associated with impaired bidirectional synaptic plasticity, including LTP, LTD, and depotentiation (Shen et al., 2008; Cerovic et al., 2015; Trusel et al., 2015). Specifically, ERK has a crucial role in LTP induction as ERK inhibitors attenuate or even eliminate LTP in dorsomedial striatum (Xie et al., 2009). In Nr4a1-EGFP mice, we performed single-cell patch clamp recordings of EGFP ${ }^{+}$ and EGFP ${ }^{-}$neurons located in the center of striosomes. Based on the percentages of $\mathrm{EGFP}^{+}$neurons that are also $\mathrm{Drd1}^{+}$( Fig. 2a-c), we estimated that half of the EGFP ${ }^{+}$ cells from which we recorded were dMSNs and half were iMSNs. In the WT mice, in which MSN subtypes are indistinguishable morphologically, we assumed that the majority of the neurons from which we recorded are located in the matrix, which represents $\sim 90 \%$ of the striatum, with a 1:1 distribution between dMSNs and iMSNs. Overall, EGFP ${ }^{+}$neurons were more excitable than those recorded in WT mice, as determined by left-shifted current-frequency plots and lower rheobase currents (Fig. $6 a, b$; two-way ANOVA with genotype factor, $F_{(2,57)}=$ $7.421, p=0.0014)$. This might be due to an intrinsic increased excitability of striosomal neurons compared with matrix (Crittenden et al., 2017). Membrane resistance and spike threshold were equal in WT, and $\mathrm{EGFP}^{+}$and EGFP $^{-}$MSNs $\left(F_{(2,50)}=0.7388, p=0.4828\right.$ and $F_{(2,49)}=$ $0.5219, p=0.5967)$, but resting membrane potential (rheobase) was more depolarized in $\mathrm{EGFP}^{+}$neurons
$\left(F_{(2,55)}=4.303, p=0.0183\right.$; Fig. 6c-f $)$. Notably, we observed the difference in excitability in mixed populations of MSNs despite the fact that $D_{1}$ dMSNs are less excitable than $D_{2}$ iMSNs (Gertler et al., 2008; Planert et al., 2010) and the EGFP ${ }^{+}$neurons are equally likely to be $D_{1}$ or $D_{2}$.

Using a standard high-frequency stimulation protocol (Calabresi et al., 1997), we observed that LTD induction was equivalent in WT neurons (cells registered from wildtype mice) and EGFP ${ }^{+}$neurons (Fig. 6g,h; unpaired twotailed $t$ test, $\left.t_{(15)}=1.868, p=0.0815\right)$. LTP, however, could not be induced in the majority of $\mathrm{EGFP}^{+}$neurons (only two of seven) using the same protocol, whereas it was readily induced in five of seven WT MSNs (data not shown). As we were unable to reliably obtain LTP in $\mathrm{EGFP}^{+}$neurons with whole single-cell recordings, we also used field recordings to confirm this genotype-dependent effect, and assayed LTP, LTD, and paired-pulse ratio. In field recordings, LTD and paired-pulse ratio in Nr4a1eGFP striatum were equivalent to those in WT (two-way ANOVA with genotype factor, $F_{(1,19)}=0.2400, p=$ 0.6298; data not shown), but LTP, albeit present, was significantly decreased in amplitude (Fig. 6i,j; unpaired two-tailed $t$ test, $\left.t_{(12)}=3.011, p=0.0108\right)$. The normal paired-pulse ratio suggests that the corticostriatal glutamate release and AMPA receptor function are unaltered by Nr4a1 overexpression. The differences in LTP induction observed both by single-cell and field recordings strongly suggest an alteration in the activation of MSNs by constitutive overexpression of $\mathrm{Nr} 4 \mathrm{a} 1$, but these data do not allow us to distinguish between the effects of genotype and compartment.

\section{Nr4a1 overexpression impacts the expression of Drd1 signaling pathway components}

Dopamine induces $\mathrm{pERK}$ via a signal transduction pathway consisting of Drd1, G $\alpha_{\text {olf }}$, and AC5, the activation of which results in production of the second messenger CAMP. The downstream effectors include CAMP-dependent protein kinase, DARPP-32, protein phosphatase-1 (PP1), and striatal-enriched tyrosine phosphatase 61 (STEP61; Girault, 2012a). We performed additional qPCR assays of genes in the Drd1 pathway and biochemical assays to assess its function. We identified a decrease in mRNA levels of Drd1 $\left(F_{(2,21)}=4.755, p=0.0198\right.$; and $\left.t_{(21)}=3.084, p=0.0056\right)$ and Adcy5 (AC5; $F_{(2,24)}=7.618, p=0.0027$; and $t_{(24)}=$ $3.859, p=0.008)$, and an increase in Ptpn5 (STEP61; $F_{(2,24)}$ $=10.15, p=0.0006$; and $\left.t_{(24)}=4332, p=0.0002\right)$ and Ppp1c (PP1; $F_{(2,24)}=7.275, p=0.0034 ;$ and $t_{(24)}=3.301, p$ 
a
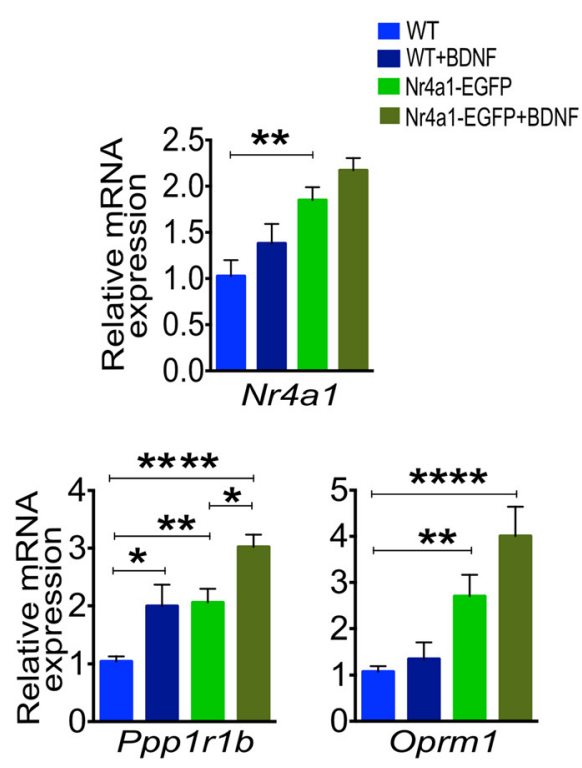

b
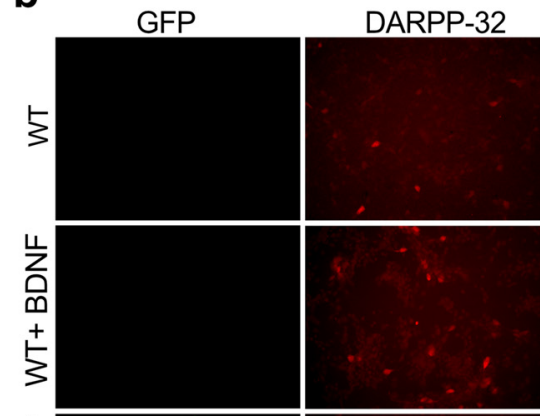

Merge + DAPI
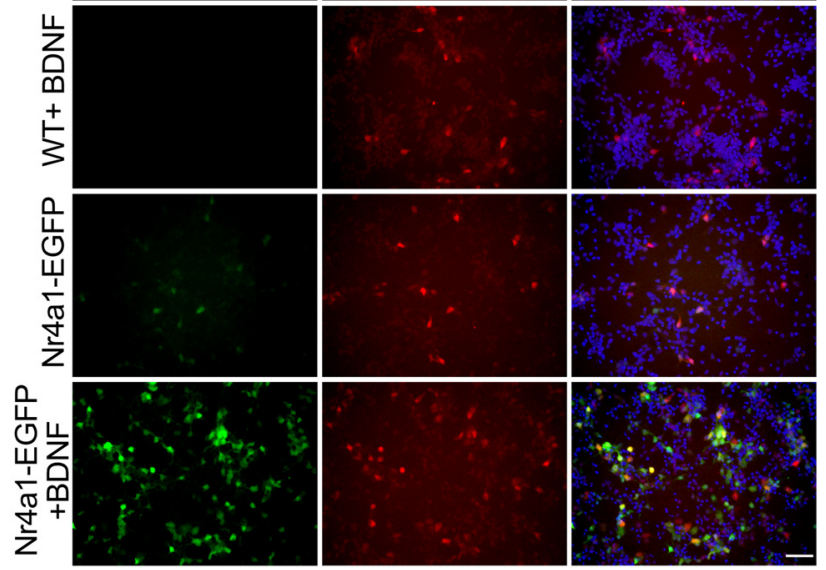

d
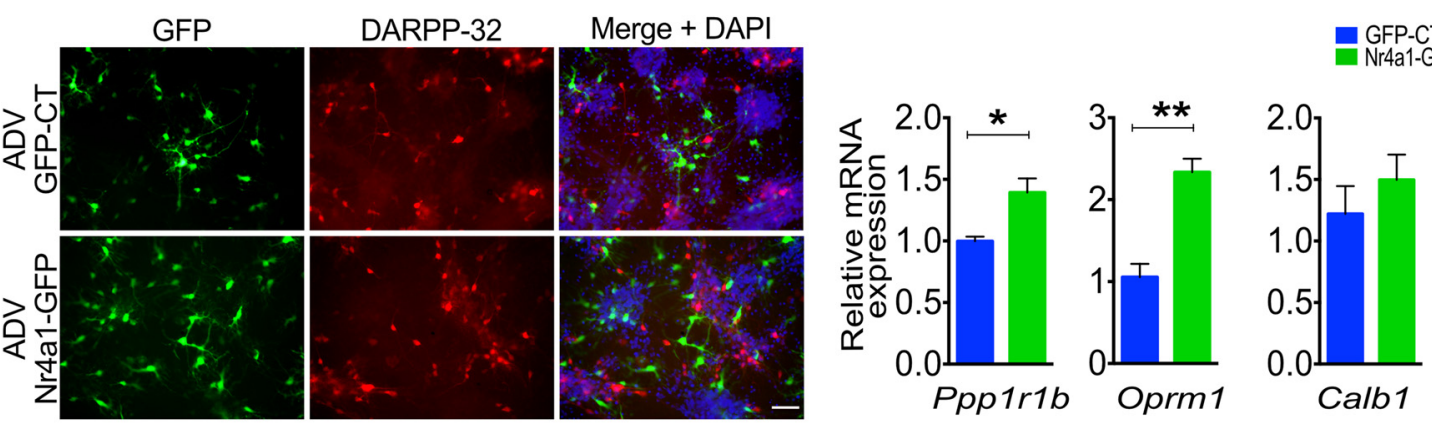

Figure 3. Nr4a1 promotes the maturation of specific medium spiny neuronal phenotypes, including of Oprm1, a striosomal marker. a, qRT-PCR assay of Nr4a1, Ppp1r1b, and Oprm1 mRNAs on DIV7 WT and Nr4a1-eGFP primary striatal neurons treated with BDNF $25 \mathrm{ng} / \mathrm{ml}$ vs $0.1 \%$ BSA reveals that $N r 4 a 1$ is overexpressed in Nr4a1-eGFP neurons $\left(F_{(3,15)}=10.15, p=0.007\right.$; WT vs $N r 4 a 1$-eGFP: $\left.t_{(15)}=3695, p=0.0022\right)$ and is associated with an increase in Ppp1r1b $\left(F_{(3,27)}=10.04, p=0.0001\right.$; WT vs Nr4a1-eGFP: $t_{(27)}=2.910$, $p=0.0072)$ and Oprm1 $\left(F_{(3,13)}=17.77, p<0.0001\right.$; WT vs Nr4a1-eGFP $\left.t_{(13)}=3.338, p=0.0053\right)$. BDNF treatment is additive for both Ppp1r1b (WT vs WT+BDNF: $t_{(27)}=2.729, p=0.011$; WT vs Nr4a1-eGFP+BDNF: $t_{(27)}=5.479, p=0.0001 ;$ Nr4a1-eGFP vs Nr4a1-eGFP+BDNF: $t_{(27)}=2.688, p=0.0127$ ) and Oprm1 (WT vs Nr4a1-eGFP+BDNF: $\left.t_{(13)}=5.944, p=0.0001\right) . n=5$ samples/genotype. One-way ANOVA corrected for multiple comparisons (Sidak's test): $* p<0.05, * * p<0.01, * * * * p<0.0001$. Data are presented as the mean \pm SEM. $\boldsymbol{b}$, Representative Pp1r1b/DARPP-32 staining on DIV7 WT and Nr4a1-eGFP primary striatal neurons treated with BDNF $(25 \mathrm{ng} / \mathrm{ml})$ shows a relatively increased number of DARPP-32-immunopositive cells in Nr4a1-eGFP primary cultures. The effects of increased Nr4a1 and BDNF are additive. Scale bars, $50 \mu \mathrm{m}$. c, Representative DARPP-32 immunolabeling of WT primary striatal neurons $96 \mathrm{~h}$ after transduction with ADV-GFP CT vs ADV-Nr4a1-eGFP showing increase in DARPP-32-immunopositive cells in the cultures overexpressing Nr4a1. Scale bars, $50 \mu \mathrm{m}$. $\boldsymbol{d}$, qRT-PCR assay shows increases in Ppp1r1b $\left(t_{(6)}=2.551, p=0.0434\right)$ and Oprm1 $\left(t_{(6)}=5.505, p=0.0015\right)$ mRNA levels in wild-type primary striatal neurons $96 \mathrm{~h}$ after transduction with ADV-Nr4a1-GFP. $n=5$ samples/treatment, two-tailed unpaired $t$ test: $* p<0.05$, $* * p<0.01$. Data are presented as the mean \pm SEM.

$=0.003$; Fig. 7a) in Nr4a1-eGFP mice relative to WT littermates. Gnal $\left(\mathrm{G} \alpha_{\text {olf }}\right)$ mRNA was equal in all three genotypes $\left(F_{(2,15)}=0.3226, p=0.7291\right.$; Fig 7a). Despite the decrease in AC5 mRNA, the baseline cAMP level was equal to WT (unpaired $t$ test, $t_{(8)}=1.367, p=0.2089$ ) and, consistent with this finding, the level of AC5 protein was normal (unpaired $t$ test, $\left.t_{(7)}=0.6399, p=0.5426\right)$, indicating posttranscriptional regulation (Fig. 7b). However, the ability of AC5 to be activated by Drd1 stimulation was diminished (Fig. 7c; $F_{(1,4)}=25.96, p=0.007$; and $t_{(8)}=4.659, p=$
0.0016), as evidenced also by the reduced efficacy of cAMP response to dopamine stimulation (Fig. 7d; unpaired $t$ test, $\left.t_{(4)}=3.484, p=0.0253\right)$. This suggests that the pool of activatable AC5 is diminished.

We next used forskolin and G $\alpha$ s-GTP $\gamma \mathrm{S}$ titrations to bypass $\operatorname{Drd1-G} \alpha_{\text {olf }}$ inputs and assay only the AC5 activation step. These experiments revealed that Nr4a1-eGFP mice have reduced the potency of $A C$ activation compared with WT mice at equal dosage (Fig.7e; two-way ANOVA genotype factor; Forskolin: $F_{(1,12)}=12.76, p=$ 
a
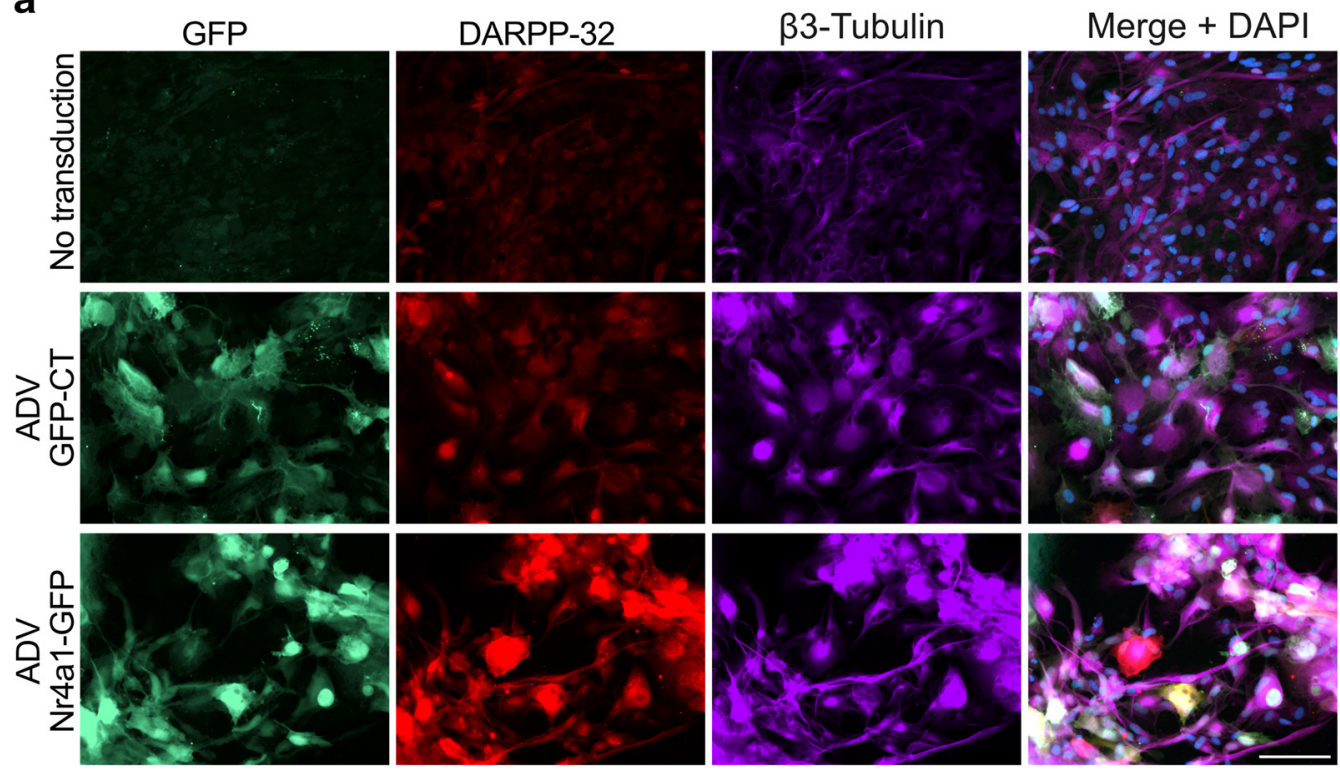

b
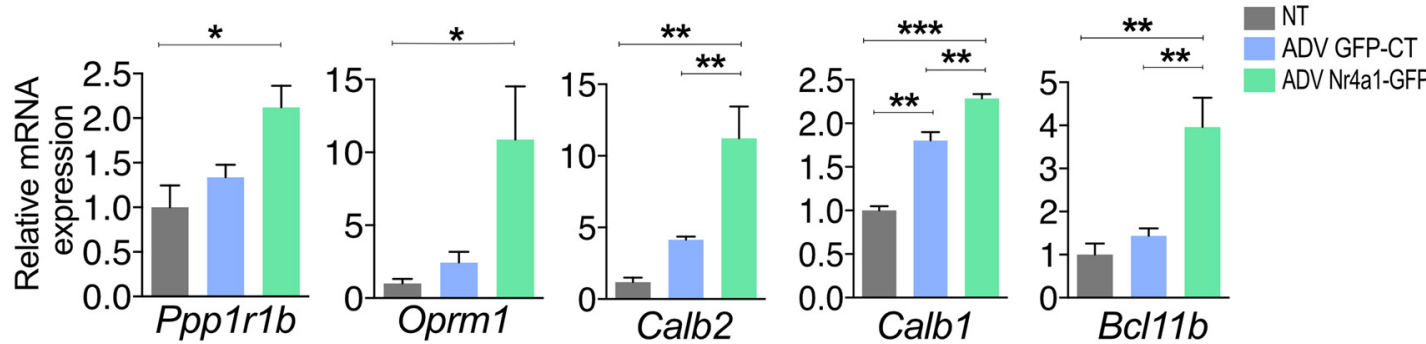

Figure 4. Nr4a1 promotes the differentiation of MSNs phenotypes in human iPSC-derived NPCs into medium spiny neurons. a, Immunolabeling of DARPP-32 and $\beta$ III tubulin in iPSC-derived NSCs, untreated, vs transduction with ADV-GFP or ADV-NR4A1-GFP shows that Nr4a1 induces the upregulation of DARPP-32 and $\beta$ III tubulin. Scale bar, $100 \mu \mathrm{m} . \boldsymbol{b}$, qRT-PCR assays show an increase in Ppp1r1b $\left(F_{(2,6)}=7.173, p=0.0256\right.$; NT vs Nr4a1-GFP: $\left.t_{(6)}=3.691, p=0.0102\right)$, Oprm1 $\left(F_{(2,6)}=6.105, p=0.0358 ;\right.$ NT vs Nr4a1-GFP: $\left.t_{(6)}=3.234, p=0.0178\right)$, Calb2 $\left(F_{(2,6)}=15.75, p=0.0041\right.$; NT vs Nr4a1-GFP: $t_{(6)}=5.461, p=0.0016$; GFP-CT vs Nr4a1-GFP: $\left.t_{(6)}=3.854, p=0.008\right)$, Calb1 $\left(F_{(2,5)}=72.94, p=0.0002 ;\right.$ NT vs Nr4a1-GFP: $t_{(5)}=11.63, p=0.0001 ;$ GFP vs Nr4a1-GFP: $\left.t_{(5)}=4.357, p=0.0073\right)$, and $B c / 11 b\left(F_{(2,6)}=13.69, p=0.0058\right.$; NT vs Nr4a1-GFP: $t_{(6)}=4.848, p=0.0029 ;$ GFP vs Nr4a1-GFP: $\left.t_{(6)}=4.132, p=0.0068\right)$ mRNA levels in human iPSC-derived NSCs transduced with ADV-Nr4a1-GFP for $14 \mathrm{~d}$. $n=3$ samples for each group. One-way ANOVA corrected for multiple comparisons (Tukey's test): $* p<0.05, * * p<0.01, * * * p<0.001$. Data are presented as the mean \pm SEM.

0.0038; G $\alpha$ S-GTP $\left.\gamma \mathrm{S}: F_{(1,24)}=35.19, p<0.0001\right)$, suggesting that the regulation of AC5 by sensitizing/desensitizing factors is abnormal.

\section{Discussion}

Nr4a1 is a member of the Nur family of nuclear receptors, which are expressed in specific patterns in the CNS and periphery. In the brain, a high level of Nr4a1/Nur77 is found in dopaminoceptive striatal MSNs, where it is enriched in the striosomes (Davis and Puhl, 2011). The Nr4a1-null mouse has been characterized to some extent (Gilbert et al., 2006), but its striosomal architecture has not been described, and the effects of Nr4a1 overexpression have not been reported. In this study, we show that the GENSAT Nr4a1-eGFP reporter mouse expresses twice the normal level of Nr4a1 mRNA in the striatum, allowing us to examine the effects of Nr4a1 overexpression and deletion on specific aspects of striatal development and function. However, the mechanism leading to
Nr4a1 overexpression in this animal model remains unknown.

We found that in the presence of increased Nr4a1, several markers of striosomal MSNs are increased both in the early postnatal period and in the adult, whereas markers of matrix MSNs are largely unchanged. Although striosomes are clearly demarcated in the absence of Nr4a1, they are smaller and occupy a lower percentage of the total area. Moreover, Nr4a1 overexpression in humanderived NSCs differentiated with Activin A further promotes their maturation toward a general MSN phenotype. Notably, Nr4a1 promotes maturation of the medium spiny neuron in vitro, including several striosome markers. The exact mechanism via which $\mathrm{Nr} 4 \mathrm{a} 1$ regulates striosome formation is unknown, but a microarray study of hippocampal neurons in which Nr4a1 is overexpressed revealed the upregulation of several transcription factors also involved in striatal development, including Sp8, Meis1, and Gsx1 (Chen et al., 2014). We conclude that a 
a

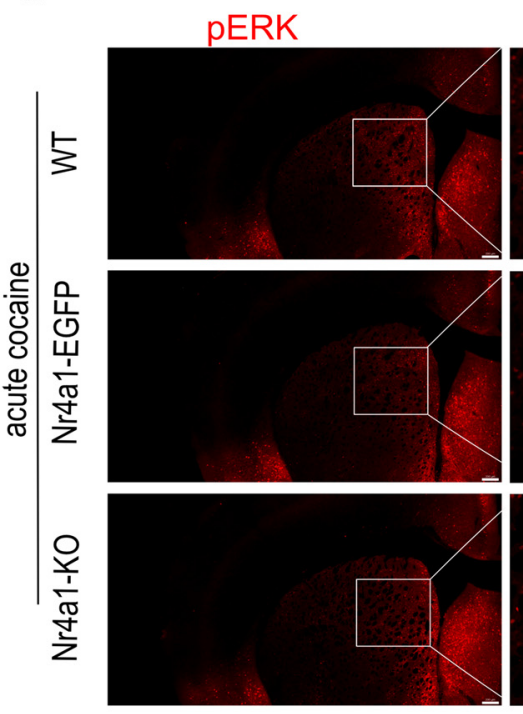

b
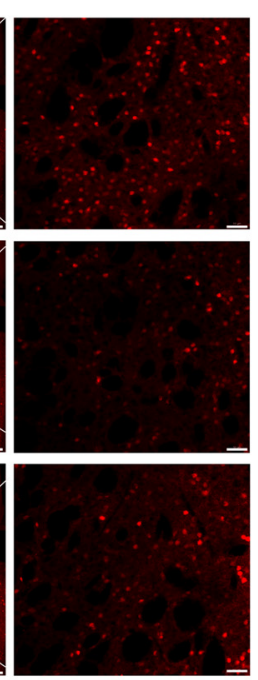
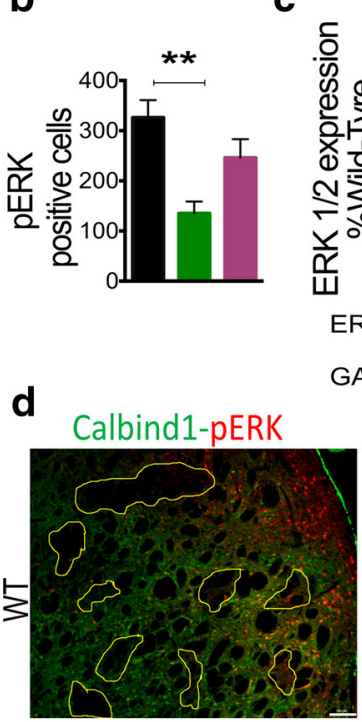

C

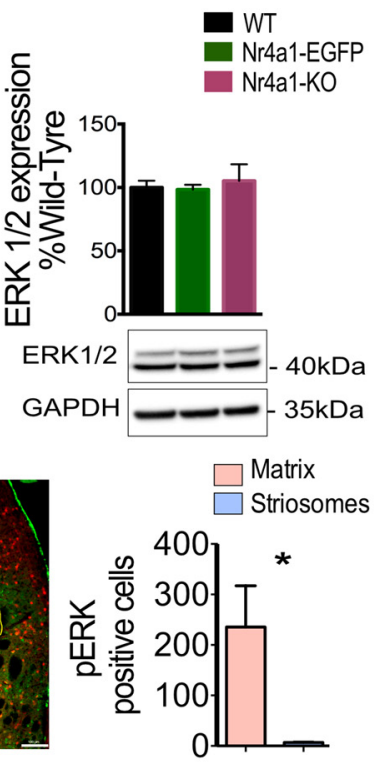

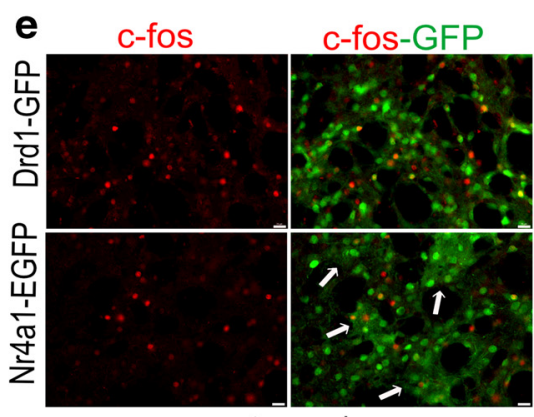

acute cocaine f

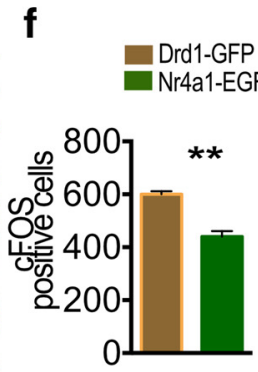

g

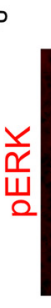

WT

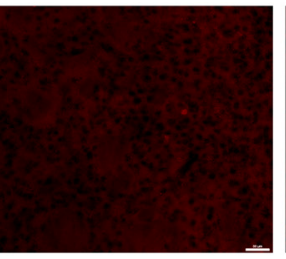

acute cocaine + MK-801
Nr4a1-EGFP

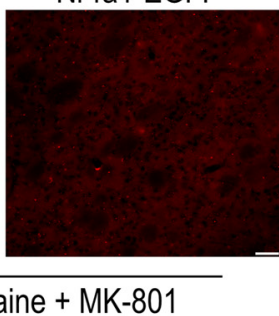

h

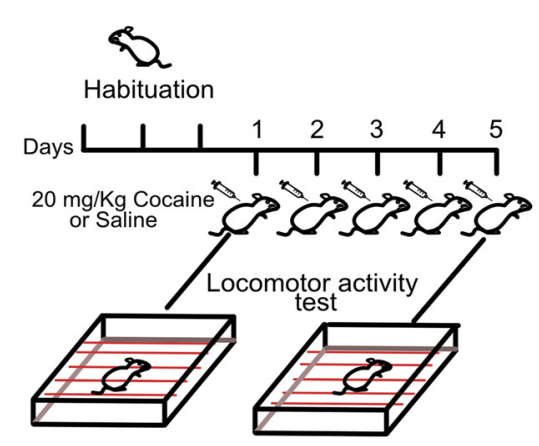

i
- WT Saline Day 1

- WT Saline Day 5

- WT Cocaine Day 1

WT Cocaine Day 5

- Nr4a1-EGFP Saline Day 1

- Nr4a1-EGFP Saline Day 5

Nr4a1-EGFP Cocaine Day 1

Nr4a1-EGFP Cocaine Day 5

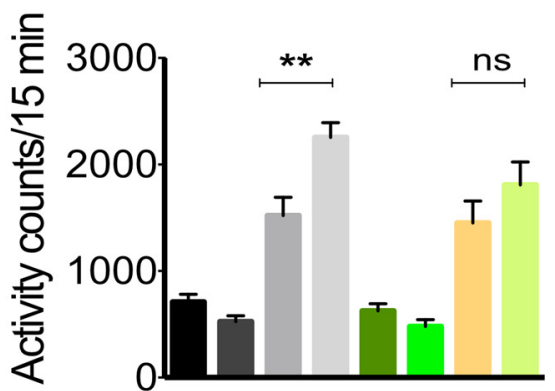

Figure 5. Nr4a1 overexpression reduces the induction of phosphorylation of ERK and c-fos after acute cocaine injection and impairs locomotor sensitization to chronic cocaine. a, Representative pERK immunolabeling indicating the dorsomedial region of interest and fixed area used for the quantification of $\mathrm{pERK}^{+}$cells in the striatum of 4-month-old WT, Nr4a1-eGFP, and Nr4a1-null mice 10 min after a single intraperitoneal injection of cocaine $(20 \mathrm{mg} / \mathrm{kg})$. Scale bars: 200 and $50 \mu \mathrm{m}$. $\boldsymbol{b}$, Quantification of $\boldsymbol{a}$ showing a relative reduced induction of pERK ${ }^{+}$cells in Nr4a1-eGFP mice $\left(F_{(2,8)}=7.281, p=0.0158\right.$; WT vs Nr4a1-eGFP: $\left.t_{(8)}=3.816, p=0.0051\right) . n=4$ mice/genotype; one-way ANOVA corrected for multiple comparisons (Bonferroni's correction): $* p<0.05$. Data are presented as the mean \pm SEM. $c$, ERK $1 / 2$ basal protein levels are equal in 4-month-old WT, Nr4a1-eGFP, and Nr4a1-null mice $\left(F_{(2,9)}=1.340, p=\right.$ 0.3094). $n=8$ mice/genotype. One-way ANOVA corrected for multiple comparisons (Sidak's test). Data are presented as the mean \pm SEM. $\boldsymbol{d}$, Calbindin and pERK immunolabeling shows that the induction of pERK occurs predominantly in the matrix compartment after a single intraperitoneal injection of cocaine $(20 \mathrm{mg} / \mathrm{kg})$. Scale bars, $100 \mu \mathrm{m}$. The graph shows the quantification of pERK ${ }^{+}$cells in matrix and striosomes in sections from bregma $0.86 \mathrm{~mm} . n=3$ mice, unpaired $t$ test: $t_{(2.003)}=4.702, * p=0.0423$. Data are 
continued

presented as the mean \pm SEM. e, c-fos and GFP immunolabeling in the dorsal striatum of Drd1-eGFP and Nr4a1-eGFP adult mice $1 \mathrm{~h}$ after a single intraperitoneal injection of cocaine (20 mg/kg), indicating relatively reduced c-fos induction in Nr4a1-eGFP mice. Arrows indicate c-fos labeling in the GFP ${ }^{+}$striosomes in the Nr4a1-eGFP mice. Scale bars, $50 \mu \mathrm{m}$. $\boldsymbol{f}$, Quantification of c-fos ${ }^{+}$cells in Drd1-eGFP and Nr4a1-eGFP adult mice shown in e. $n=3$ mice/genotype and treatment, unpaired $t$ test: $t_{(4)}=6.721$, $* * p=0.0026$. Data are presented as the mean \pm SEM. $\boldsymbol{g}$, pERK immunostaining in WT and Nr4a1-eGFP mice after the injection NMDA antagonist MK-801 $(0.1 \mathrm{mg} / \mathrm{kg})$ followed $30 \mathrm{~min}$ later by a single injection of cocaine $(20 \mathrm{mg} / \mathrm{kg})$ shows the abolition of pERK induction. Scale bars, $50 \mu \mathrm{m}$. $\boldsymbol{h}$, Schematic representation of treatments used for the induction of locomotor sensitization to cocaine. $\boldsymbol{i}$, Nr4a1-eGFP mice show decreased locomotor sensitization to chronic cocaine use relative to WT mice. One-way ANOVA corrected for multiple comparisons (Bonferroni's correction; $F_{(7,108)}=8.639, p<0.0001$; WT cocaine day 1 vs WT cocaine day 5 : $t_{(108)}=3.705$, $* * p=$ 0.003; Nr4a1-eGFP cocaine day 1 vs Nr4a1-eGFP cocaine day $\left.5: t_{(108)}=0.6920, p=0.4904\right)$. $n=15$ mice/genotype, One-way ANOVA corrected for multiple comparisons (Bonferroni's correction). Data are presented as the mean \pm SEM. ns $=$ non-significant.

wild-type level of $\mathrm{Nr} 4 \mathrm{a} 1$ is required for normal striosome development and maintenance, suggesting unique functions of Nr4a1 and the absence of compensation by other members of the Nur family.

Nr4a1 deletion alters striatal response to dopamine agonists and antagonists, and the data herein show that overexpression leads to dysregulation of striatal plasticity and response to external stimuli. It remains to be determined how much of this is due to constitutive overexpression and/or the increased induction of $\mathrm{Nr} 4 \mathrm{a} 1$ as an IEG due to the BAC transgene. Notably, the acute effects may be mitigated to some extent by the decreased induction of pERK, which is required for the induction of Nr4a1 transcription (Bourhis et al., 2008; Yue et al., 2017). Genetic disruption of $\mathrm{Nr} 4 \mathrm{a} 1$ in rats has recently been shown to reduce the development of LIDs (Rouillard et al., 2018), but pERK level was not assayed in these animals. We are attempting to distinguish between the effects of these opposing activities on ERK phosphorylation.

Focusing on direct pathway function, we found that Nr4a1 overexpression impairs Drd1 signaling, reducing cocaine-induced phosphorylation of ERK, locomotor sensitization to cocaine, and LTP. We found dysregulation of multiple components of this signal transduction pathway that may contribute to decreased Drd1 signaling (Girault et al., 2007; Girault, 2012a,b), but not all in the same direction, making it difficult to attribute any changes to one specific molecule. Overall, we conclude that Nr4a1 overexpression compromises AC5 availability reducing the efficacy of its responses to stimulatory GPCR inputs. As AC5 is the predominant cyclase in MSNs (Lee et al., 2002), it is unlikely that decreased $A C$ activation reflects the dysfunction of an alternate cyclase. Interestingly, an increase in $\mathrm{G}_{\mathrm{i} \alpha}$ inputs could reduce AC5 activation, and Oprm1, which is increased in Nr4a1-eGFP MSNs, is a $\mathrm{G}_{\mathrm{i} \alpha}$ coupled receptor (Chakrabarti et al., 1995; Saidak et al., 2006; Lamberts et al., 2011; Traynor, 2012). Activation of AC5 via Oprm1 is required for morphine-induced locomotor activity (Kim et al., 2006). Therefore, chronically increased MOR tone could impact cyclase activation. Likewise, with our current knowledge, we are unable to pinpoint the etiology of ERK dysregulation. Increased activity of PP1 could decrease ERK phosphorylation (for review, see Pascoli et al., 2014), as could a genetic, albeit compensatory, increase in STEP61, as constitutive deletion of STEP leads to an increase in pERK1/2 levels (García-Forn et al., 2018). Conversely, CalDEG-GEFII (called Rasgrp1) is increased in striosomes in a rat model of LIDs, and its dysregulation in the presence of an increase in Nr4a1 may also contribute to the regulation of ERK phosphorylation (Crittenden et al., 2009), but the possible increase in activity of this pathway due to increased Nr4a1 clearly does not overcome whatever is inhibiting the phosphorylation of ERK.

Not surprisingly, the motor and signal transduction abnormalities in the Nr4a1-eGFP mice are associated with striatal electrophysiological abnormalities, which require further investigation. The decreased induction of pERK, the apparent reduction in LTP, and the lack of locomotor sensitization to cocaine are internally consistent. Changes in excitability may contribute to alteration in networks and plasticity, thereby impacting the response to psychostimulant (for review, see Crittenden and Graybiel, 2011; Cao et al., 2018). How striosomes may impact movement and response to psychostimulants remains an open question that should be further studied using methods in which striosomes and Drd1 are delineated in the absence of any molecular changes, so that effects of both compartmentalization and MSN subtypes can be distinguished. The $D_{1} R$ proportion of striosomes is highly dependent on their location and the relative expression of Oprm1 and the neuropeptides SP and ENK (Tajima and Fukuda, 2013; Miyamoto et al., 2018), the latter of which corresponds with the distribution of $\mathrm{Nr} 4 \mathrm{a1}$. Here we concluded that Nr4a1-EGFP is expressed equivalently in dMSNs and iMSNs, whereas Davis and Puhl (2011) reported an enrichment of Nr4a1-EGFP in the dMSNs. This discrepancy may arise from their use of Drd1 immunolabeling to identify dMSNs and in the location of the striosomes.

The composite effects of Nr4a1 overexpression are extremely complex and may also alter Drd2-mediated function and cholinergic interneuron activity (e.g., via opioidergic stimulation; Ponterio et al., 2013). We did not examine the morphology of MSNs, but, in the hippocampus, Nr4a1 overexpression eliminates neuronal spines (Chen et al., 2014) via transcriptional regulation of cytoskeletal proteins. Nr4a1 also regulates spine density in the striatum (Tian et al., 2010), which impacts Parkinson's disease and addiction phenotypes (Villalba and Smith, 2013). Finally, Nr4a1 is expressed in glia and is a key regulator of the inflammatory response in microglia and astrocytes (Ipseiz et al., 2014; Rothe et al., 2017; Popichak et al., 2018), another mechanism via 
a

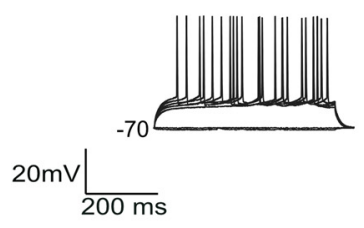

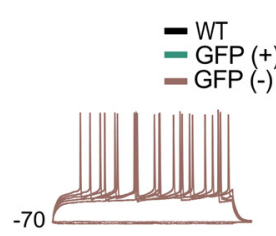

b

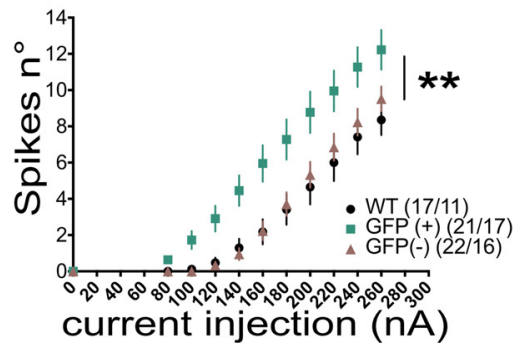

C

d

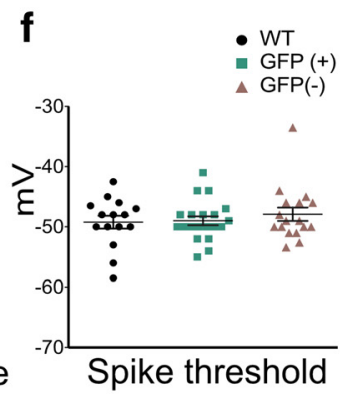

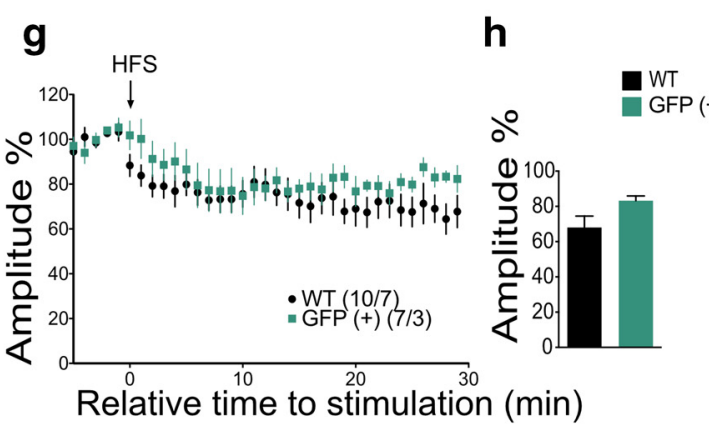

Single cell recording e

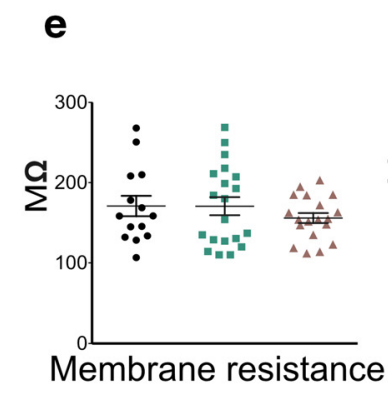

i

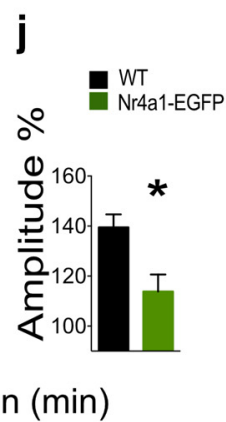

Field recording

Figure 6. Characterization of electrophysiological properties of dorsomedial striosomal MSNs and the impact of Nr4a1 overexpression on striatal synaptic excitability and plasticity. a, Action potential sample traces from single cells derived from the dorsal striatum in WT mice and in the center of the striosomes for GFP ${ }^{+}$and GFP ${ }^{-}$neurons from Nr4a1-eGFP mice. $\boldsymbol{b}$, Number of action potentials as a function of injected current intensity in WT, $\mathrm{GFP}^{+}$, and $\mathrm{GFP}^{-}$neurons indicate that neuronal action potentials are increased in GFP $^{+}$neurons. Two-way ANOVA with genotype factor $\left(F_{(2,57)}=7.421, p=0.0014\right) . n \geq 17 /$ genotype and cell type; $* * p<0.01$. Data are presented as the mean \pm SEM. $c$, Resting membrane potential is more depolarized in GFP ${ }^{+}$neurons compared with WT (WT MSNs: average, $-75.8 \mathrm{mV}, n=17$ cells; $\mathrm{GFP}^{+} \mathrm{MSNs}$ : average, $-71.7 \mathrm{mV}, n=22$; $\mathrm{GFP}^{-} \mathrm{MSNs}$ average, $-74.2 \mathrm{mV}, n=21$ ). One-way ANOVA followed by Bonferroni's multiple-comparisons test: $F_{(2,55)}=4.303, p=0.0183$, $* p<0.05$. Data are presented as the mean \pm SEM. $\boldsymbol{d}$, Rheobase current is lower in GFP ${ }^{+}$neurons relative to WT and GFP ${ }^{-}$MSNs (WT MSNs: average, 171.1 pA, $n$ $=17$ cells; GFP $^{+}$MSNs: average, $134.1 \mathrm{pA}, n=22$; GFP ${ }^{-}$MSNs: average, $164.7 \mathrm{pA}, n=21$ ). One-way ANOVA-Bonferroni's multiple-comparison test, $F_{(2,51)}=4.342, p=0.0181 ; * p<0.05$. Data presented as $\pm \mathrm{SEM}$. e, Membrane resistance recorded in voltage-clamp experiments is equal in the three cell types. WT, $n=10$; $\mathrm{GFP}^{+}$and $\mathrm{GFP}^{-}, n=16$. One-way ANOVA-Bonferroni's multiple-comparison test: $F_{(2,50)}=0.7388, p=0.4828$. Data are presented as the mean \pm SEM. $\boldsymbol{f}$, Spike threshold is equal in the three cell types. WT, $n=15$; $\mathrm{GFP}^{+}$and $\mathrm{GFP}^{-}, n=19$. One-way ANOVA-Bonferroni's multiple-comparison test: $F_{(2,49)}=0.5219, p=$ 0.5967. Data are presented as the mean \pm SEM. $g$. Whole-cell patch-clamp recordings of long-term synaptic depression (LTD) induced by high-frequency stimulation in WT and GFP ${ }^{+}$MSNs showing overlapping traces for both genotypes. Data are presented as the mean \pm SEM. $\boldsymbol{h}$, Bar graph representing the average of the last 5 min after LTD induction in WT and GFP ${ }^{+}$MSNs indicating no significant differences between the two groups: WT, 10 recordings/7 mice; GFP ${ }^{+}, 7$ recordings/3 mice. Unpaired two-tailed $t$ test, $t_{(15)}=1.868, p=0.0815$. Data are presented as the mean \pm SEM. $\boldsymbol{i}$, LTP assayed in field recordings in WT and Nr4a1-eGFP shows reduced LTP in Nr4a1-eGFP mice after high-frequency stimulation. Data are presented as the mean \pm SEM. $\boldsymbol{j}$, Bar graph representing the average of the last $5 \mathrm{~min}$ after LTP induction in field recordings (7 recordings and 3 mice for both genotypes). Unpaired two-tailed $t$ test: $t_{(12)}=3.011, p=0.0108 ; * p<0.05$; Data are presented as the mean \pm SEM. 

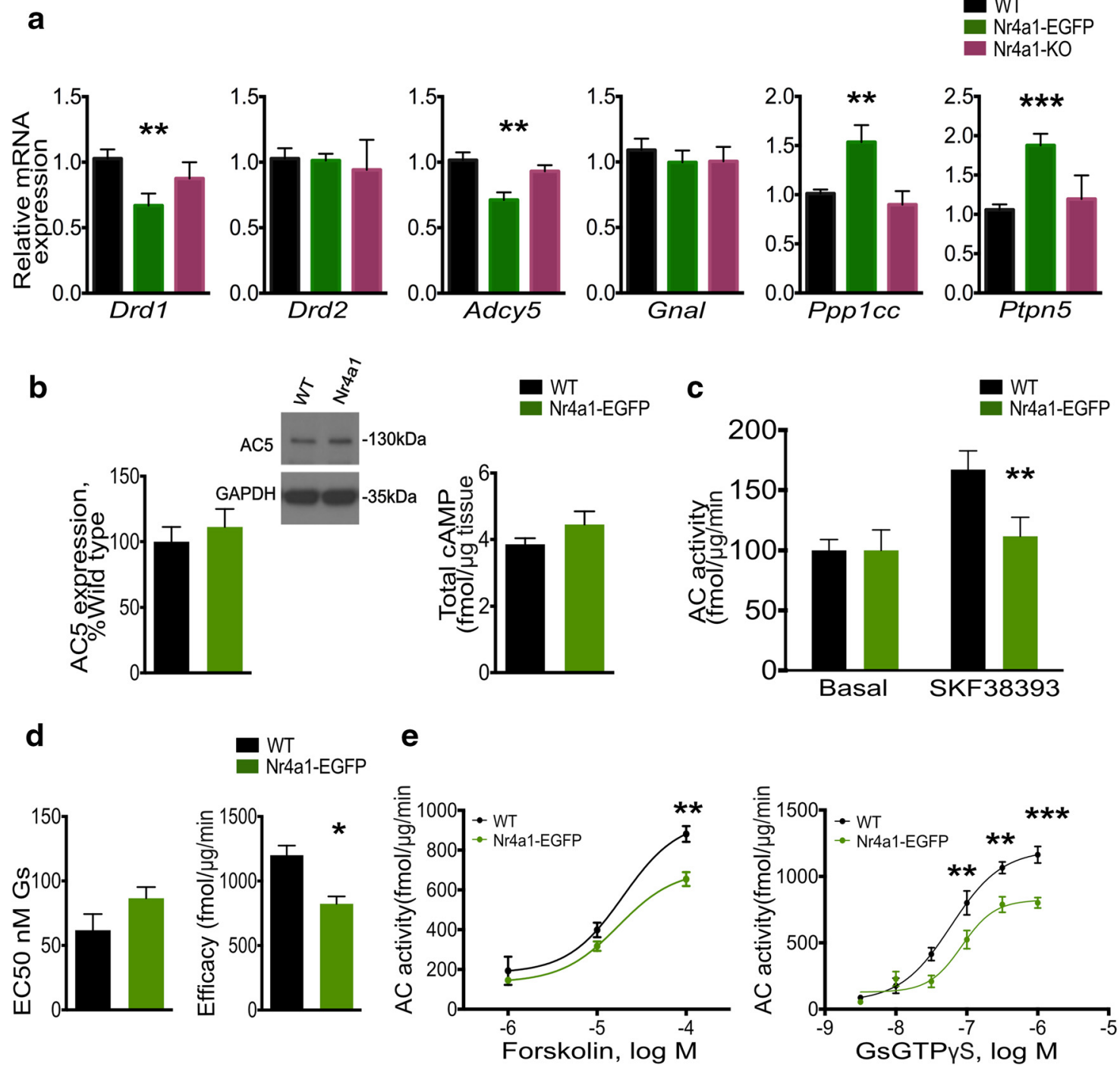

Figure 7. Nr4a1 overexpression impacts the activation of Drd1signaling. a, qRT-PCR assay of mRNA levels of Drd1 signaling pathway components in the striatum of 4-month-old WT, Nr4a1-eGFP, and Nr4a1-null mice shows a decrease of $D r d 1\left(F_{(2,21)}=4.755, p=\right.$ $\left.0.0198 ; t_{(21)}=3.084, p=0.0056\right)$ and $A d y c 5$, and an increase of $P p p 1 c c\left(F_{(2,24)}=7.275, p=0.0034 ; t_{(24)}=3.301, p=0.003\right)$ and Ptpn5 $\left(F_{(2,24)}=10.15, p=0.0006 ; t_{(24)}=4332, p=0.0002\right)$ in Nr4a1-eGFP mice. $n \geq 5$ mice/genotype; One-way ANOVA corrected for multiple comparisons (Sidak's test): $* p<0.05, * * p<0.01, * * * p<0.001$. Data are presented as the mean \pm SEM. $\boldsymbol{b}$, Western blot of AC5 protein shows equal levels in WT and Nr4a1-eGFP striatum, normalized to GAPDH. Unpaired $t$ test, $t_{(7)}=0.6399, p=$ 0.5426; $n \geq 4$ /genotype. Data are presented as the mean \pm SEM. The basal striatal cAMP level in Nr4a1-eGFP mice is equal to wild type. Unpaired $t$ test, $t_{(8)}=1.367, p=0.2089 . n \geq 4 /$ genotype. Data are presented as the mean \pm SEM. $\boldsymbol{c}$, AC5 activity on Drd1 stimulation with SKF38393 indicates a reduction of the response in Nr4a1-eGFP mice. $n=3$ mice/genotype. Two-way ANOVA corrected for multiple comparisons (Sidak's test) $F_{(1,4)}=25.96, p=0.007, t_{(8)}=4.659, * * p=0.0016$. Data are presented as the mean \pm SEM. $\boldsymbol{d}$, E50 and AC5 stimulation efficacy in striatal membrane preparation from Nr4a1-eGFP and wild-type mice, showing a decrease in AC5 efficacy in Nr4a1-eGFP mice. $n=3$ mice; unpaired $t$ test, $t_{(4)}=3.484, * p=0.0253$. Data are presented as the mean \pm SEM. e, Gs-GTP $\gamma$ S and Forskolin AC5 activity-titration curves in striatal membrane preparation from Nr4a1-eGFP and wild-type mice, indicating a reduced AC5 activation plateau in Nr4a1-eGFP mice. $n=3$ mice. Two-way ANOVA corrected for multiple comparisons (Sidak's test) genotype factor forskolin: $F_{(1,12)}=12.76, p=0.0038$; at $10 \mathrm{~mm}$ : $t_{(12)}=3.941, p=0.002$; G $\alpha \mathrm{S}-\mathrm{GTP} \gamma \mathrm{S}$ : $F_{(1,24)}=35.19, p<0.0001$; at 0.1 and $0.5 \mu \mathrm{M}: t_{(24)}=2.711, * * p=0.0122$; and $1 \mu \mathrm{M}: t_{(24)}=3650$, $* * * p=0.0013$. Data are presented as the mean \pm SEM.

which Nr4a1 may impact the response to drugs of abuse (Russo et al., 2009)

In summary, constitutive overexpression (and deletion) of $\mathrm{Nr} 4 \mathrm{a} 1$ in the striatum has profound effects on striosome development and phenotype, and multiple Drd1-related neuronal functions. The exact mechanisms remain to be determined, but the pathways regulated by $\mathrm{Nr} 4 \mathrm{a} 1$ may represent novel, druggable approaches to pathologic states associated with increased pERK (e.g., LIDs and cocaine sensitization). In addition, the overexpression of Nr4a1 in the Nr4a1-eGFP mouse and the changes in striatal structure dopaminoceptive function should be 
taken into account when interpreting data derived from this reporter line.

\section{References}

Alcacer C, Santini E, Valjent E, Gaven F, Girault J-A, Hervé D (2012) $\mathrm{G} \alpha$ (olf) mutation allows parsing the role of cAMP-dependent and extracellular signal-regulated kinase-dependent signaling in L-3,4dihydroxyphenylalanine-induced dyskinesia. J Neurosci 32:59005910.

Beaudry G, Langlois MC, Weppe I, Rouillard C, Lévesque D (2000) Contrasting patterns and cellular specificity of transcriptional regulation of the nuclear receptor nerve growth factor-inducible $B$ by haloperidol and clozapine in the rat forebrain. J Neurochem 75: 1694-1702.

Bourhis E, Maheux J, Rouillard C, Lévesque D (2008) Extracellular signal-regulated kinases (ERK) and protein kinase C (PKC) activities are involved in the modulation of Nur77 and Nor-1 expression by dopaminergic drugs. J Neurochem 106:875-888.

Brimblecombe KR, Cragg SJ (2017) The striosome and matrix compartments of the striatum: a path through the labyrinth from neurochemistry toward function. ACS Chem Neurosci 8:235-242.

Calabresi P, Saiardi A, Pisani A, Baik J-H, Centonze D, Mercuri NB, Bernardi G, Borrelli E (1997) Abnormal synaptic plasticity in the striatum of mice lacking dopamine $D_{2}$ receptors. J Neurosci 17: 4536-4544.

Cao J, Willett JA, Dorris DM, Meitzen J (2018) Sex differences in medium spiny neuron excitability and glutamatergic synaptic input: heterogeneity across striatal regions and evidence for estradiol-dependent sexual differentiation. Front Endocrinol 9:173.

Cerovic M, Bagetta V, Pendolino V, Ghiglieri V, Fasano S, Morella I, Hardingham N, Heuer A, Papale A, Marchisella F, Giampà C, Calabresi P, Picconi B, Brambilla R (2015) Derangement of Rasguanine nucleotide-releasing factor 1 (Ras-GRF1) and extracellular signal-regulated kinase (ERK) dependent striatal plasticity in L-DOPA-induced dyskinesia. Biol Psychiatry 77:106-115.

Chakrabarti S, Prather PL, Yu L, Law PY, Loh HH (1995) Expression of the mu-opioid receptor in $\mathrm{CHO}$ cells: ability of mu-opioid ligands to promote alpha-azidoanilido[32P]GTP labeling of multiple G protein alpha subunits. J Neurochem 64:2534-2543.

Chen E, Lallai V, Sherafat Y, Grimes NP, Pushkin AN, Fowler JP, Fowler CD (2018) Altered baseline and nicotine-mediated behavioral and cholinergic profiles in ChAT-Cre mouse lines. J Neurosci 38:2177-2188.

Chen Y, Wang Y, Ertürk A, Kallop D, Jiang Z, Weimer RM, Kaminker J, Sheng M (2014) Activity-induced Nr4a1 regulates spine density and distribution pattern of excitatory synapses in pyramidal neurons. Neuron 83:431-443.

Crittenden JR, Graybiel AM (2011) Basal ganglia disorders associated with imbalances in the striatal striosome and matrix compartments. Front Neuroanat 5:59.

Crittenden JR, Cantuti-Castelvetri I, Saka E, Keller-McGandy CE, Hernandez LF, Kett LR, Young AB, Standaert DG, Graybiel AM (2009) Dysregulation of CalDAG-GEFI and CalDAG-GEFII predicts the severity of motor side-effects induced by anti-parkinsonian therapy. Proc Natl Acad Sci U S A 106:2892-2896.

Crittenden JR, Lacey CJ, Weng F-J, Garrison CE, Gibson DJ, Lin Y, Graybiel AM (2017) Striatal cholinergic interneurons modulate spike-timing in striosomes and matrix by an amphetaminesensitive mechanism. Front Neuroanat 11:20.

Davis MI, Puhl HL (2011) Nr4a1-eGFP is a marker of striosomematrix architecture, development and activity in the extended striatum. PLoS One 6:e16619.

Ethier I, Kagechika H, Shudo K, Rouillard C, Lévesque D (2004) Docosahexaenoic acid reduces haloperidol-induced dyskinesias in mice: involvement of Nur77 and retinoid receptors. Biol Psychiatry 56:522-526.

García-Forn M, Martínez-Torres S, García-Díaz Barriga G, Alberch J, Milà M, Azkona G, Pérez-Navarro E (2018) Pharmacogenetic mod- ulation of STEP improves motor and cognitive function in a mouse model of Huntington's disease. Neurobiol Dis 120:88-97.

Gertler TS, Chan CS, Surmeier DJ (2008) Dichotomous anatomical properties of adult striatal medium spiny neurons. J Neurosci 28:10814-10824.

Giguère V (1999) Orphan nuclear receptors: from gene to function. Endocr Rev 20:689-725.

Gilbert F, Morissette M, St-Hilaire M, Paquet B, Rouillard C, Di Paolo T, Lévesque D (2006) Nur77 gene knockout alters dopamine neuron biochemical activity and dopamine turnover. Biol Psychiatry 60:538-547.

Girasole AE, Lum MY, Nathaniel D, Bair-Marshall CJ, Guenthner CJ, Luo L, Kreitzer AC, Nelson AB (2018) A subpopulation of striatal neurons mediates levodopa-induced dyskinesia. Neuron 97:787795.e6.

Girault J-A (2012a) Signaling in striatal neurons: the phosphoproteins of reward, addiction, and dyskinesia. Prog Mol Biol Transl Sci 106:33-62.

Girault J-A (2012b) Integrating neurotransmission in striatal medium spiny neurons. Adv Exp Med Biol 970:407-429.

Girault J-A, Valjent E, Caboche J, Hervé D (2007) ERK2: a logical AND gate critical for drug-induced plasticity? Curr Opin Pharmacol 7:77-85.

Ipseiz N, Uderhardt S, Scholtysek C, Steffen M, Schabbauer G, Bozec A, Schett G, Krönke G (2014) The nuclear receptor Nr4a1 mediates anti-inflammatory effects of apoptotic cells. J Immunol 192:4852-4858.

Keilani S, Chandwani S, Dolios G, Bogush A, Beck H, Hatzopoulos AK, Rao GN, Thomas EA, Wang R, Ehrlich ME (2012) Egr-1 induces DARPP-32 expression in striatal medium spiny neurons via a conserved intragenic element. J Neurosci 32:6808-6818.

Kim K-S, Lee K-W, Lee K-W, Im J-Y, Yoo JY, Kim S-W, Lee J-K, Nestler EJ, Han P-L (2006) Adenylyl cyclase type 5 (AC5) is an essential mediator of morphine action. Proc Natl Acad Sci U S A 103:3908-3913.

Kolisnyk B, Guzman MS, Raulic S, Fan J, Magalhães AC, Feng G, Gros R, Prado VF, Prado MAM (2013) ChAT-ChR2-EYFP mice have enhanced motor endurance but show deficits in attention and several additional cognitive domains. J Neurosci 33:10427-10438.

Kramer PF, Christensen CH, Hazelwood LA, Dobi A, Bock R, Sibley DR, Mateo Y, Alvarez VA (2011) Dopamine D2 receptor overexpression alters behavior and physiology in Drd2-EGFP mice. $J$ Neurosci 31:126-132.

Kreitzer AC, Malenka RC (2007) Endocannabinoid-mediated rescue of striatal LTD and motor deficits in Parkinson's disease models. Nature 445:643-647.

Lamberts JT, Jutkiewicz EM, Mortensen RM, Traynor JR (2011) Mu-opioid receptor coupling to $\mathrm{G} \alpha \mathrm{O}$ plays an important role in opioid antinociception. Neuropsychopharmacology 36:20412053.

Lee K-W, Hong J-H, Choi IY, Che Y, Lee J-K, Yang S-D, Song C-W, Kang HS, Lee J-H, Noh JS, Shin H-S, Han P-L (2002) Impaired $D_{2}$ dopamine receptor function in mice lacking type 5 adenylyl cyclase. J Neurosci 22:7931-7940.

Lee SL, Wesselschmidt RL, Linette GP, Kanagawa O, Russell JH, Milbrandt J (1995) Unimpaired thymic and peripheral T cell death in mice lacking the nuclear receptor NGFI-B (Nur77). Science 269:532-535

Livak KJ, Schmittgen TD (2001) Analysis of relative gene expression data using real-time quantitative PCR and the 2(-Delta Delta C(T)) method. Methods 25:402-408.

Mahmoudi S, Samadi P, Gilbert F, Ouattara B, Morissette M, Grégoire L, Rouillard C, Di Paolo T, Lévesque D (2009) Nur77 mRNA levels and L-Dopa-induced dyskinesias in MPTP monkeys treated with docosahexaenoic acid. Neurobiol Dis 36:213-222.

Mahmoudi S, Blanchet PJ, Lévesque D (2013) Haloperidol-induced striatal Nur77 expression in a non-human primate model of tardive dyskinesia. Eur J Neurosci 38:2192-2198.

Miyamoto Y, Katayama S, Shigematsu N, Nishi A, Fukuda T (2018) Striosome-based map of the mouse striatum that is conformable 
to both cortical afferent topography and uneven distributions of dopamine D1 and D2 receptor-expressing cells. Brain Struct Funct 223:4275-4291.

Partridge JG, Tang KC, Lovinger DM (2000) Regional and postnatal heterogeneity of activity-dependent long-term changes in synaptic efficacy in the dorsal striatum. J Neurophysiol 84:1422-1429.

Pascoli V, Cahill E, Bellivier F, Caboche J, Vanhoutte P (2014) Extracellular signal-regulated protein kinases 1 and 2 activation by addictive drugs: a signal toward pathological adaptation. Biol Psychiatry 76:917-926.

Planert H, Szydlowski SN, Hjorth JJJ, Grillner S, Silberberg G (2010) Dynamics of synaptic transmission between fast-spiking interneurons and striatal projection neurons of the direct and indirect pathways. J Neurosci 30:3499-3507.

Ponterio G, Tassone A, Sciamanna G, Riahi E, Vanni V, Bonsi P, Pisani A (2013) Powerful inhibitory action of mu opioid receptors (MOR) on cholinergic interneuron excitability in the dorsal striatum. Neuropharmacology 75:78-85.

Popichak KA, Hammond SL, Moreno JA, Afzali MF, Backos DS, Slayden RD, Safe S, Tjalkens RB (2018) Compensatory expression of Nur77 and Nurr1 regulates NF- $\kappa$ B-dependent inflammatory signaling in astrocytes. Mol Pharmacol 94:1174-1186.

Rothe T, Ipseiz N, Faas M, Lang S, Perez-Branguli F, Metzger D, Ichinose H, Winner B, Schett G, Krönke G (2017) The nuclear receptor Nr4a1 acts as a microglia rheostat and serves as a therapeutic target in autoimmune-driven central nervous system inflammation. J Immunol 198:3878-3885.

Rouillard C, Baillargeon J, Paquet B, St-Hilaire M, Maheux J, Lévesque C, Darlix N, Majeur S, Lévesque D (2018) Genetic disruption of the nuclear receptor Nur77 (Nr4a1) in rat reduces dopamine cell loss and I-Dopa-induced dyskinesia in experimental Parkinson's disease. Exp Neurol 304:143-153.

Russo SJ, Wilkinson MB, Mazei-Robison MS, Dietz DM, Maze I, Krishnan V, Renthal W, Graham A, Birnbaum SG, Green TA, Robison B, Lesselyong A, Perrotti LI, Bolaños CA, Kumar A, Clark MS, Neumaier JF, Neve RL, Bhakar AL, Barker PA, et al. (2009) Nuclear factor $\kappa \mathrm{B}$ signaling regulates neuronal morphology and cocaine reward. J Neurosci 29:3529-3537.

Saidak Z, Blake-Palmer K, Hay DL, Northup JK, Glass M (2006) Differential activation of $\mathrm{G}$-proteins by $\mu$-opioid receptor agonists. Br J Pharmacol 147:671-680.

Santini E, Valjent E, Usiello A, Carta M, Borgkvist A, Girault J-A, Hervé D, Greengard P, Fisone G (2007) Critical involvement of CAMP/DARPP-32 and extracellular signal-regulated protein kinase signaling in L-DOPA-induced dyskinesia. J Neurosci 27:69957005.

Shen W, Flajolet M, Greengard P, Surmeier DJ (2008) Dichotomous dopaminergic control of striatal synaptic plasticity. Science 321: 848-851.

Shuen JA, Chen M, Gloss B, Calakos N (2008) Drd1a-tdTomato BAC transgenic mice for simultaneous visualization of medium spiny neurons in the direct and indirect pathways of the basal ganglia. $J$ Neurosci 28:2681-2685.

St-Hilaire M, Landry E, Lévesque D, Rouillard C (2003a) Denervation and repeated L-DOPA induce a coordinate expression of the transcription factor NGFI-B in striatal projection pathways in hemiparkinsonian rats. Neurobiol Dis 14:98-109.

St-Hilaire M, Tremblay P-O, Lévesque D, Barden N, Rouillard C (2003b) Effects of cocaine on c-fos and NGFI-B mRNA expression in transgenic mice underexpressing glucocorticoid receptors. Neuropsychopharmacology 28:478-489.
Tajima K, Fukuda T (2013) Region-specific diversity of striosomes in the mouse striatum revealed by the differential immunoreactivities for mu-opioid receptor, substance $\mathrm{P}$, and enkephalin. Neuroscience 241:215-228.

Tian X, Kai L, Hockberger PE, Wokosin DL, Surmeier DJ (2010) MEF-2 regulates activity-dependent spine loss in striatopallidal medium spiny neurons. Mol Cell Neurosci 44:94-108.

Ting JT, Feng G (2014) Recombineering strategies for developing next generation BAC transgenic tools for optogenetics and beyond. Front Behav Neurosci 8:111.

Traynor $J$ (2012) $\mu$-Opioid receptors and regulators of $\mathrm{G}$ protein signaling (RGS) proteins: from a symposium on new concepts in mu-opioid pharmacology. Drug Alcohol Depend 121:173-180.

Trusel M, Cavaccini A, Gritti M, Greco B, Saintot P-P, Nazzaro C, Cerovic M, Morella I, Brambilla R, Tonini R (2015) Coordinated regulation of synaptic plasticity at striatopallidal and striatonigral neurons orchestrates motor control. Cell Rep 13:1353-1365.

Valjent E, Pagès C, Hervé D, Girault J-A, Caboche J (2004) Addictive and non-addictive drugs induce distinct and specific patterns of ERK activation in mouse brain. Eur J Neurosci 19:1826-1836.

Valjent E, Hervé D, Girault J-A (2005) [Drugs of abuse, protein phosphatases, and ERK pathway]. Med Sci (Paris) 21:453-454.

Valjent E, Corvol J-C, Trzaskos JM, Girault J-A, Hervé D (2006) Role of the ERK pathway in psychostimulant-induced locomotor sensitization. BMC Neurosci 7:20.

Villalba RM, Smith Y (2013) Differential striatal spine pathology in Parkinson's disease and cocaine addiction: a key role of dopamine? Neuroscience 251:2-20.

Werme M, Olson L, Brené S (2000a) NGFI-B and nor1 mRNAs are upregulated in brain reward pathways by drugs of abuse: different effects in Fischer and Lewis rats. Brain Res Mol Brain Res 76:1824

Werme M, Ringholm A, Olson L, Brené S (2000b) Differential patterns of induction of NGFI-B, Nor1 and c-fos mRNAs in striatal subregions by haloperidol and clozapine. Brain Res 863:112-119.

Westin JE, Vercammen L, Strome EM, Konradi C, Cenci MA (2007) Spatiotemporal pattern of striatal ERK1/2 phosphorylation in a rat model of L-DOPA-induced dyskinesia and the role of dopamine D1 receptors. Biol Psychiatry 62:800-810.

Xie GQ, Wang SJ, Li J, Cui SZ, Zhou R, Chen L, Yuan XR (2009) Ethanol attenuates the HFS-induced, ERK-mediated LTP in a dose-dependent manner in rat striatum. Alcohol Clin Exp Res 33:121-128.

Xie K, Masuho I, Brand C, Dessauer CW, Martemyanov KA (2012) The complex of $\mathrm{G}$ protein regulator RGS9-2/G $\beta 5$ controls sensitization and signaling kinetics of type 5 adenylyl cyclase. Sci Signal 5:ra63.

Xie K, Masuho I, Shih C-C, Cao Y, Sasaki K, Lai CWJ, Han P-L, Ueda $\mathrm{H}$, Dessauer CW, Ehrlich ME, Xu B, Willardson BM, Martemyanov KA (2015) Stable G protein-effector complexes in striatal neurons: mechanism of assembly and role in neurotransmitter signaling. Elife 4:e10451.

Xu M (2008) c-Fos is an intracellular regulator of cocaine-induced long-term changes. Ann N Y Acad Sci 1139:1-9.

Yue J, Lai F, Beckedorff F, Zhang A, Pastori C, Shiekhattar R (2017) Integrator orchestrates RAS/ERK1/2 signaling transcriptional programs. Genes Dev 31:1809-1820.

Zetterström RH, Williams R, Perlmann T, Olson L (1996) Cellular expression of the immediate early transcription factors Nurr1 and NGFI-B suggests a gene regulatory role in several brain regions including the nigrostriatal dopamine system. Brain Res Mol Brain Res 41:111-120. 